https://helda.helsinki.fi

\title{
Energetics of interannual temperature variability
}

\section{Räisänen, Jouni}

2019-03

Räisänen , J 2019 , ' Energetics of interannual temperature variability ' , Climate dynamics : observational, theoretical and computational research on the climate system, vol. 52 , no. 5-6 , pp. 3139-3156 . https://doi.org/10.1007/s00382-018-4306-0

http://hdl.handle.net/10138/303626

https://doi.org/10.1007/s00382-018-4306-0

acceptedVersion

Downloaded from Helda, University of Helsinki institutional repository.

This is an electronic reprint of the original article.

This reprint may differ from the original in pagination and typographic detail.

Please cite the original version. 


\section{Energetics of interannual temperature variability}

Jouni Räisänen

Institute for Atmospheric and Earth System Research / Physics,

Faculty of Science, University of Helsinki

Submitted to Climate Dynamics, 29 September 2017

Third revision, 11 June 2018

\section{Corresponding author}

Jouni Räisänen

Institute for Atmospheric and Earth System Research / Physics,

Faculty of Science

P.O. Box 64, FI-00014 University of Helsinki, Finland

Phone +358-2941 50872

Email: jouni.raisanen@helsinki.fi

orcid.org/0000-0003-3657-1588 


\section{Abstract}

2 Energetics of interannual temperature variability in the years 1980-2016 is studied

3 using two reanalysis data sets. Monthly temperature anomalies are decomposed to

4 contributions from the net surface energy flux, atmospheric energy convergence

5 minus storage (CONV), and processes that affect the top-of-the-atmosphere

6 radiation balance. The analysis reveals a strong compensation between the net

7 surface heat flux and CONV over the ice-free oceans, with the former driving the

8 temperature variability over the tropical oceans and the latter at higher latitudes.

9 CONV also makes a dominant contribution to temperature anomalies in the winter

10 hemisphere extratopical continents. During the summer half-year and in the tropics,

11 however, variations in cloudiness dominate the temperature variability over land,

12 while the contribution of CONV is modest or even negative. The latter reflects the

13 diffusion-like behaviour of short-term atmospheric variability, which acts to spread

14 out the local, to a large extent cloud-induced temperature anomalies to larger areas.

15 The ERA-Interim and MERRA2 reanalyses largely agree on the general energy

16 budget features of interannual temperature variability, although substantial

17 quantitative differences occur in some of the individual terms.

19 KEYWORDS: temperature variability, energy budget, reanalysis, ERA-Interim, 20 MERRA2 
 \\ 1. Introduction}

24 Interannual variations in climate are of great practical importance. In particular,

25 extended periods of anomalously hot or cold weather have large impacts on nature

26 and society. Recent prominent examples include the heat waves in central Europe

27 in 2003 (García-Herrera et al. 2010) and in Russia in 2010 (Barriopedro et al. 2011),

28 and the cold winter in eastern North America in 2013-1014 (Yu and Zhang 2015).

29 Nonetheless, such extremes are just the tip of the iceberg within an omnipresent

30 continuum of temperature variability, the magnitude of which depends on both the

31 season and the location. The largest interannual temperature variability is observed

32 over ice-covered oceans and high-latitude continents in winter, whereas the

33 variability over the low-to-mid-latitude oceans is relatively muted outside of the

34 eastern Tropical Pacific (Holmes et al. 2016; see also Figs. 3a and 4a-b).

36 A fraction of interannual temperature variability is driven by external forcing such

37 as major volcanic eruptions (Robock 2000; Paik and Min 2017). However, most of

38 it results from the chaotic internal dynamics of the climate system: the variations in

39 atmospheric and oceanic circulation, and the resulting perturbations in sea and land

40 surface conditions. The influence of the oceans is largest at low latitudes, where the

41 atmospheric circulation and temperatures are strongly controlled by the distribution

42 of sea surface temperature (SST) (Wells 2012; Holton and Hakim 2012). In

43 particular, the El Niño - La Niña variability in the eastern-to-central equatorial

44 Pacific SSTs generates atmospheric teleconnections that profoundly affect the

45 climate all around the tropics but to some extent also in extratropical latitudes (Diaz

46 et al. 2001, Yang and DelSole 2012). However, the relative impact of SST

47 variability decreases and that of internal atmospheric dynamics increases towards

48 higher latitudes (Zwiers and Kharin 1998). The interannual SST variability over the

49 extratropical oceans is strongly regulated by variations in the atmospheric

50 circulation, whereas the ocean's effect on the extratropical atmosphere is more

51 subtle (Bjerknes 1964, Deser and Blackmon 1993). Nevertheless, there is evidence

52 that the ocean plays a more active role in generating atmospheric variability on

53 decadal than interannual time scales (Kushnir 1994).

55 Although ultimately driven by atmospheric and oceanic circulation, variations in near-surface temperature are modulated by feedbacks that affect the atmospheric 
57 and surface energy budget. For example, both reduced cloudiness (which increases

58 the absorption of solar radiation) and reduced soil moisture (which decreases the

59 evaporative cooling of the surface) have been identified as important ingredients in

60 European heat waves (Black et al. 2004, Fischer et al. 2007). Consistent with both

61 mechanisms, the correlation between monthly temperature and precipitation is

62 widely negative over midlatitude continents in summer and in tropical land areas

63 (Trenberth and Shea 2005). As another example, Park et al. (2015) used the Climate

64 Feedback - Response Analysis Method (Lu and Cai 2009) to explain the

65 temperature differences between winters with a strong and a weak Siberian high.

66 They found that lower temperatures in central Siberia in winters with a strong

67 Siberian high result from a combination of factors, including cold advection,

68 increased surface cooling due to larger sensible heat flux, and weaker greenhouse

69 effect due to reduced water vapour and cloud water content. Hu et al. (2016) used

70 the same method to energetically explain the different distribution of surface

71 temperature anomalies in Eastern and Central Pacific El Niños. Although the heat

72 flux from the ocean was identified as the main cause of surface temperature

73 anomalies in both cases, the larger warming in the Eastern Pacific during the

74 Eastern Pacific El Niños was attributed to a stronger water vapour feedback in this

75 area.

77 Despite the previous work, a systematic view on the energetics of interannual 78 temperature variability still appears to be lacking. Variations in several factors, 79 among others atmospheric energy transport, surface-atmosphere energy exchange, 80 surface albedo, clouds, and the atmospheric clear-sky greenhouse effect might all 81 be important under at least some circumstances. But how important are they in 82 general, in different parts of the world and in different seasons? This study aims to 83 give at least an initial answer to this question, focusing on the interannual variability 84 of monthly mean temperatures. The study is based on data sets from two modern 85 atmospheric reanalyses (Section 2) and an energy balance framework that was 86 earlier used for analysis of model-simulated $\mathrm{CO}_{2}$-induced temperatute changes by 87 Räisänen (2017; hereafter R17) (Section 3). The results are reported in Section 4, 88 and some aspects of their physical interpretation are discussed further in Section 5. 89 The main conclusions are presented in Section 6. 


\section{2. Data sets}

92 Data from the ERA-Interim (Dee et al. 2011) and MERRA2 (Gelaro et al. 2017)

93 reanalyses for the years 1980-2016 are used. The variables required by the energy

94 balance decomposition include surface air temperature, total cloudiness, surface

95 latent and sensible heat fluxes, and surface and top-of-the-atmosphere (TOA)

96 downward and upward short-wave (SW) and long-wave (LW) radiative fluxes for

97 both all-sky and clear-sky conditions (Table 1 in R17). These variables were

98 downloaded as monthly means in a $2.5^{\circ} \times 2.5^{\circ}$ latitude-longitude grid.

99

100 For ERA-Interim, surface pressure and six atmospheric variables ( $u$ and $v$ wind,

101 vertical velocity $\omega$, temperature, geopotential and specific humidity) at 37 pressure

102 levels were additionally downloaded at $0.75^{\circ} \times 0.75^{\circ}$ horizontal resolution and 6-h

103 time interval. This large (2.8 TB) data set was used for explicit calculation of the

104 atmospheric energy flux convergence term (Sections 3.2 and 4.5 and Appendix A)

105 that was inferred as a residual in the other parts of the analysis.

106

107 The suitability of reanalysis data sets for energy budget analysis might be 108 questioned because reanalyses violate energy conservation (e.g., Trenberth and 109 Fasullo 2013) and show spurious large-scale trends associated with changes in the 110 observing system (Allan et al. 2014). However, because the focus in this study is 111 on interannual climate variability, the energy budget biases only matter to the extent 112 that they vary from year to year. We assessed this issue in two ways, by analyzing

113 the analysis increments in MERRA2 and by studying the mutual agreement and 114 differences between ERA-Interim and MERRA2. The analysis increments were 115 found to be large, but their impact on our main diagnostic results is moderated by 116 their relatively weak correlation with the actual temperature anomalies (Section 117 S1.1 in the Supplementary material). Furthermore, ERA-Interim and MERRA2 118 give a largely consistent view on the energetics of interannual temperature 119 variability, although there are in many cases substantial quantitative differences 120 between these two reanalyses (Section 4.1). 


\section{3. Methods}

123 This section first describes the main features of the R17 energy balance method and

124 its application to the interannual variability of monthly mean temperatures. After

125 this, the methods used in the explicit calculation of atmospheric energy flux 126 convergence in the ERA-Interim reanalysis are summarized. They are described in 127 more detail in Appendix A.

\subsection{Energy balance framework}

131 The R17 method is built around the concept of effective planetary emissivity $\varepsilon_{e f f}$, 132 which connects the surface air temperature $T$ to the outgoing longwave (LW) 133 radiation $L$ at the TOA

$$
L=\varepsilon_{e f f} \sigma T^{4}
$$

135 and is (in broad terms, see Section 4.4) an inverse measure of the atmospheric

136 greenhouse effect. Thus, warm anomalies in $T$ require either a negative anomaly in $137 \varepsilon_{e f f}$, a positive anomaly in $L$, or both. Combining (1) with the atmospheric energy 138 budget equation gives

$$
\varepsilon_{e f f} \sigma T^{4}=S-G+\left(C-\frac{\partial E}{\partial t}\right)
$$

140 where $S$ is net SW radiation at the TOA, $G$ net downward heat flux to the surface,

$141 C$ horizontal energy flux convergence in the atmosphere, and $E$ the total energy in 142 the atmospheric column.

143 Referring to the climatological monthly mean of variable $X$ as $X_{\text {CLIM }}$, the anomaly is

$144 \Delta X=X-X_{\text {CLIM. }}$. After also defining $[X]=\left(X+X_{\text {CLIM }}\right) / 2$, (2) leads to

$$
\sigma\left[\varepsilon_{\text {eff }}\right] \Delta\left(T^{4}\right)=\underbrace{-\sigma \Delta \varepsilon_{e f f}\left[T^{4}\right]}_{I}+\underbrace{\Delta S}_{I I} \underbrace{-\Delta G}_{I I I}+\underbrace{\Delta\left(C-\frac{\partial E}{\partial t}\right)}_{I V}
$$

146 Finally, linearizing the left side of (3) as

$$
\sigma\left[\varepsilon_{e f f}\right] \Delta\left(T^{4}\right) \approx 4 \sigma\left[\varepsilon_{e f f}\right][T]^{3} \Delta T=D \Delta T
$$

148 allows one to decompose the temperature anomaly $\Delta T$ as 


$$
\Delta T=\underbrace{L W}_{I}+\underbrace{S W}_{I I}+\underbrace{S U R F}_{I I I}+\underbrace{C O N V}_{I V}+E R R
$$

150 where the terms $I-I V$ in (3) have been divided by $D=4 \sigma\left[\varepsilon_{e f f}\right][T]^{3}$. These four 151 terms represent the temperature anomalies due to LW and SW radiation, net surface 152 energy flux, and atmospheric energy flux convergence minus storage. On the 153 average, $D \approx 3.3 \mathrm{Wm}^{-2} \mathrm{~K}^{-1}$, so that a $1 \mathrm{Wm}^{-2}$ energy perturbation is typically 154 equivalent to $0.3 \mathrm{~K}$ in temperature.

156 The linearization in (3) is performed around $\left(T+T_{\text {CLIM }}\right) / 2$ rather than $T_{\text {CLIM }}$. This 157 makes the linearization residual $E R R$ very small, with a mean absolute value of less 158 than $10^{-3} \mathrm{~K}$. On the other hand, variations in $D$ allow the means of $L W, S W, S U R F$ 159 and $C O N V$ to differ from zero when averaged over the whole period. Nevertheless, 160 their mean values are small relative to their interannual variability that is the focus 161 of this paper.

163 The terms $L W$ and $S W$ are further divided to two and five parts, respectively

$$
L W=L W_{C L E A R}+L W_{C R E}
$$

$$
S W=S W_{I N}+S W_{C L E A R-A T M}+S W_{A L B E D O}+S W_{C L O U D}+S W_{N L}
$$

In (6), $L W_{C L E A R}$ is the temperature anomaly attributed to the clear-sky greenhouse effect (anomaly of $\varepsilon_{\text {eff }}$ under clear-sky conditions) and $L W_{C R E}$ that due to the longwave cloud radiative effect. The division (7) is based on the approximate partial radiative perturbation (APRP) method (Taylor et al. 2007). The five terms represent the SW radiation anomalies associated with incoming $\mathrm{SW}$ radiation $\left(S W_{I N}\right), \mathrm{SW}$

radiative properties of the clear-sky atmosphere (SWCLEAR-ATM), surface albedo $172\left(S W_{A L B E D O}\right)$, clouds $\left(S W_{C L O U D}\right)$, and nonlinear effects $\left(S W_{N L}\right)$. Different notations 173 are used for the two cloud terms ( $L W_{C R E}$ and $\left.S W_{C L O U D}\right)$ because of the difference in 174 their way of calculation. $L W_{C R E}$ is based directly on the anomaly in the cloud 175 radiative effect, which may be affected by variations in the clear-sky radiative 176 properties of the atmosphere in addition to those in clouds. By contrast, $S W_{C L O U D}$ 177 attempts to isolate the effect of cloud anomalies on the SW radiation budget by 178 explicit although highly simplified modelling of the radiative transfer. For further 179 details, see R17. 
181 The focus in this paper is on interannual variability. To separate this from long-term

182 climate change, all the anomalies were linearly detrended before the energy budget

183 decomposition. Conversely, $X_{C L I M}$ as given above Eq. (3) was defined by the least-

184 square trend line fitted for each calendar month separately.

\subsection{Direct calculation of the convergence term}

188 For most parts of the analysis, $C O N V$ in (5) was calculated from the difference of 189 the net surface and TOA energy fluxes. This is straightforward but offers no 190 information on the mechanisms that contribute to CONV. Therefore, we also 191 estimated CONV directly from ERA-Interim data. In practice, the calculation of 192 energy flux convergence was replaced by calculation of three-dimensional energy 193 advection in the interest of numerical accuracy (Appendix A). However, because 194 the convergence and advection forms are physically equivalent, the word 195 "convergence" will be used when discussing the results.

197 The resulting direct estimate for $C O N V$ is

$$
C O N V_{D I R}=C O N V_{M O N}+C O N V_{S M}+S T O R
$$

199 Here $C O N V_{M O N}$ denotes the temperature anomaly attributed to the energy flux

200 convergence by the monthly mean flow, whereas $C O N V_{S M}$ results from sub201 monthly covariation between winds and atmospheric energy content. STOR 202 represents the change in the total atmospheric energy content, being positive when 203 the energy content anomaly decreases from the beginning to the end of the month 204 (term IV in (3)).

\section{4. Results}

207 To introduce the method, Fig. 1 depicts time series of January and July mean 208 temperature anomalies in central Finland $\left(62.5^{\circ} \mathrm{N}, 25^{\circ} \mathrm{E}\right)$ and their decomposition 209 to the main energy budget contributions, separately for the two reanalyses. 210 Temperature variability at this location is much larger in January than July 211 (standard deviation $\sim 4^{\circ} \mathrm{C}$ vs. $\sim 1.5^{\circ} \mathrm{C}$ ), and the energy contributions to the variability 212 are also partly different. In January, $L W_{C L E A R}, C O N V$ and to a slightly smaller extent 
213 CLOUD are the main drivers of variability, with positive values in most of the mild

214 Januarys and negative values in most of the cold Januarys. $L W_{C L E A R}$ and CLOUD

215 also act to amplify temperature variability in July, but CLOUD is more important

216 than $L W_{C L E A R}$ particularly in ERA-Interim. By contrast, CONV mostly opposes the

217 actual temperature anomalies in July. The same applies to SURF in both January

218 and July, since the anomalous net surface energy flux is directed from the

219 atmosphere to the ground in most anomalously warm months and vice versa in

220 anomalously cold months.

$222 \mathrm{SW}_{\text {ALBEDO }}$ is excluded from Fig. 1 because it is negligible in both January (due to

223 lack of solar radiation) and July (when the surface is always snow-free). $S W_{C L E A R}$ -

224 ATM is also generally small, but is substantially negative in MERRA2 after the Mt.

225 Pinatubo eruption in July 1992 and 1993 (Fig. 1d). This feature is lacking from

226 ERA-Interim, which uses prescribed climatological aerosol distributions that vary

227 seasonally but not from year to year, and thus excludes the Pinatubo eruption (Dee

228 et al. 2011, Allan et al. 2014). In MERRA2, by contrast, aerosols are simulated

229 explicitly based on emissions that vary from year to year, and observations of

230 aerosol optical depth are assimilated into the analysis (Randles et al. 2017).

232 The time series from the two reanalyses agree well on the interannual temperature 233 variations. Apart from $S W_{C L E A R-A T M}$, the same qualitatively applies to the energy

234 balance contributors to this variability. However, quantitative differences are 235 apparent. For example, in some Julys $C L O U D$ and $C O N V$ differ by several ${ }^{\circ} \mathrm{C}$ 236 between ERA-Interim and MERRA2, but to opposite directions. Recall that CONV 237 is derived from the difference of the surface and TOA net energy fluxes and any 238 reanalysis-specific errors in these fluxes are therefore directly mirrored in it.

\subsection{Magnitude of the terms and the agreement between the} two reanalyses

243 The global importance of the energy balance components is characterized in Fig. 2

244 with two statistical measures: (i) their interannual standard deviation, and (ii) their 245 contribution to the interannual standard deviation of temperature. The latter is 246 calculated as 
248 where $S D(i)$ is the standard deviation of term $i$ and $r(i)$ is the correlation between 249 term $i$ and temperature. Using the definition of correlation, one can show that the

250 SDCs sum up to the interannual standard deviation of temperature:

$$
\sum_{i} S D C(i)=S D(\Delta T)
$$

252 For Fig. 2, both the SDs and SDCs were first calculated for each month and grid 253 box and then averaged over the 12 months and the global area, so to characterize 254 the general behaviour of the terms. $S W_{I N}$ and $S W_{N L}$ are both very small, with SD < $2550.1 \mathrm{~K}$, and will therefore not be discussed further. Conversely, SURF and CONV 256 are very large, with $\mathrm{SD} \approx 5 \mathrm{~K}$. However, as discussed in Section 4.2 , they turn out 257 to have a strong mutual cancellation particularly over the oceans. $L W_{C R E}$ and $258 S W_{C L O U D}$ are also large, $S W_{C L O U D}$ being the larger. Unsurprisingly, however, there 259 is also some compensation between $L W_{C R E}$ and $S W_{C L O U D}$. We will therefore mainly 260 study their sum, denoted as CLOUD, in the rest of this paper. Although smaller than $261 \mathrm{SD}\left(S W_{C L O U D}\right), \mathrm{SD}(C L O U D)$ is also substantial (9th column of Figs. 2a,b). Of the

262 remaining terms, $L W_{C L E A R}$ is of similar magnitude with the actual monthly mean 263 temperature anomalies, whereas $S W_{C L E A R-A T M}$ and $S W_{A L B E D O}$ are relatively small on 264 the average.

266 The largest average contributors to the standard deviation of $\Delta T$ are, in this order, $267 C O N V, L W_{C L E A R}$ and CLOUD (red bars in Fig. 2). The average SDCs of $L W_{C R E}$ 268 and $S W_{\text {CLOUD }}$ are both positive in MERRA2 but the former is slightly negative in 269 ERA-Interim. On the other hand, the net surface heat flux (SURF) has a strong 270 tendency to reduce interannual temperature variability. This is particularly the case 271 over the extratropical oceans (Section 4.2).

273 The globally averaged SDs and SDCs are generally similar between the two 274 reanalyses. The largest differences occur in the SD and SDC of CLOUD and its two 275 components, $\operatorname{SDC}(S U R F)$ and $\operatorname{SDC}(C O N V)$ (recall that $C O N V$ is a residual). In 276 addition, $\operatorname{SD}\left(S W_{C L E A R-A T M}\right)$ is twice as large in MERRA2 than in ERA-Interim. This 277 is consistent with the already mentioned difference in the treatment of aerosols. 
279 To further quantify the agreement between ERA-Interim and MERRA2, the 280 correlation coefficients between the two reanalyses were calculated for (i) the full

281 space-time interannual variability of $\Delta T$ and its energy balance components during 282 the 37-year period, and the space-time variability in the (ii) SDs and (iii) SDCs over 283 the global area and the 12 calendar months (Table 1). All three correlations are 284 strongly positive for $\Delta T(>0.9)$ and most of the major energy balance components, 285 particularly $L W_{C L E A R}, S U R F$ and $C O N V(\geq 0.85)$. However, the correlations for 286 CLOUD are somewhat lower, and the difference in the treatment of aerosols 287 strongly deteriorates the agreement on $S W_{C L E A R-A T M}$. Maps of the inter-reanalysis 288 differences in the SDCs are shown in Fig. S2. Typically, the differences on the grid 289 box scale are about $10 \%$ of the two-reanalysis mean for the temperature anomalies, $29025 \%$ for $L W_{C L E A R}$, of the order of $40 \%$ for $S U R F$ and $C O N V$, and between $60 \%$ and $291100 \%$ for $S W_{C L E A R-A T M}, S W_{A L B E D O}$ and CLOUD.

293 It seems obvious that MERRA2 provides more realistic estimates of $S W_{C L E A R-A T M}$ 294 than ERA-Interim. For the other terms, the relative performance of the two 295 reanalyses is more difficult to assess, although some insight might be gained from 296 comparison with satellite data (e.g., Loeb et al. 2018) and other observational data 297 sets. In the figures shown in the rest of this paper, we will simply average the 298 statistics derived from the two reanalyses to emphasize their common features. 299 Selected maps for ERA-Interim and MERRA2 separately are included in the 300 Supplementary material (Figs. S3-S4, S6-S7 and S12-S13).

\subsection{Geographic variability}

303 The first column in Fig. 3 shows the SDs of $\Delta T$ and its main energy balance 304 components, averaged over the 12 months and the two reanalyses. The 305 corresponding SDCs are displayed in the third column, with the grey shading 306 indicating areas where their sign is not robust. The SDC is considered robust if it 307 has the same sign in the two reanalyses, and differs in at least one of them from 308 zero at the 5\% significance level based on a two-sided sign test (Appendix B). The 309 SDs and SDCs are connected by the correlation between the individual energy 310 balance terms and temperature, shown in the middle column. Following (9), the 311 "average" correlation is defined here by dividing the average SDC by the average 312 SD. 
314 Interannual temperature variability is generally larger at high than low latitudes and

315 over the continents than over the oceans (Fig. 3a). However, the Arctic Ocean and,

316 relative to its latitude, the tropical East Pacific also stand out with large variability.

317 The SD patterns for the individual energy balance components are variable (left

318 column of Fig. 3). For example, $\mathrm{SD}\left(S W_{A L B E D O}\right)$ is small in most areas, but locally

319 large where interannual variations in sea ice and snow cover are substantial: the

320 margins of the Arctic Ocean, off the coast of Antarctica, and in the Northern

321 Hemisphere extratropical continents, notably the Tibetan Plateau (Fig. 3h). By

322 contrast, $\mathrm{SD}(C L O U D)$ is large (1-4 K) nearly everywhere, but smaller over the

323 Arctic Ocean, Greenland, Antarctica, and the deserts extending from Sahara to

324 central Asia (Fig. 3k). An inspection of $L W_{C R E}$ and $S W_{C L O U D}$ separately (Fig. S5)

325 suggests two main explanations for the relatively small magnitude of $S D(C L O U D)$

326 in these areas: lack of optically thick clouds (over deserts and ice sheets), and/or

327 limited sensitivity of the TOA radiation balance to clouds where modest insolation

328 (in polar regions in most of the year) and/or high surface albedo (over ice sheets

329 and sea ice) make it easier for $L W_{C R E}$ to offset $S W_{C L O U D}$.

$\mathrm{SD}(S U R F)$ and $\mathrm{SD}(C O N V)$ are both very large over the oceans (Figs. 3n,q),

332 exceeding $8 \mathrm{~K}$ in many areas mainly in the extratropics. Their patterns are very

333 similar, which results from a strong mutual compensation. This compensation

334 reflects, on one hand, the ability of the ocean to absorb large amounts of heat with

335 only modest changes in the surface temperature, and on the other hand, the tendency

336 of the atmospheric circulation to horizontally spread the effects of local energy

337 input over a larger area (Section 5). $\mathrm{SD}(C O N V)$ is also large over the continents,

338 generally in the range 1-4 K, with the largest values at mid-to-high latitudes. By

339 contrast, $\mathrm{SD}(S U R F)$ is $<1 \mathrm{~K}$ in most land areas, due to the modest heat capacity of

340 the land surface. The main exception are the northern parts of Eurasia and North

341 America, where variations in the energy consumed by snowmelt amplify the

342 variability in the net surface heat flux in winter and spring.

344 How much a given energy term amplifies or attenuates temperature variability is

345 affected by both its standard deviation and its correlation with temperature 346 anomalies (Eq. (9)). A case in point is $L W_{C L E A R}$, which has a strong positive 
347 correlation (> 0.7) with $\Delta T$ in most extratropical areas, but a weaker or locally 348 negative correlation with $\Delta T$ in much of the tropics (Fig. 3c). This makes $349 \operatorname{SDC}\left(L W_{C L E A R}\right)$ less positive in most of the tropics than at higher latitudes (Fig. $\left.3 \mathrm{~d}\right)$,

350 although $\mathrm{SD}\left(L W_{C L E A R}\right)$ is also large in the tropics (Fig. 3b). An exception with large $351 \operatorname{SDC}\left(L W_{C L E A R}\right)$ is the equatorial East Pacific, where $L W_{C L E A R}$ is both highly variable 352 and highly correlated with temperature. The interpretation of $L W_{C L E A R}$ is discussed 353 in more detail in Section 4.4.

$355 S W_{C L E A R-A T M}$ is positively correlated with $\triangle T$ in most regions, particularly at mid356 to-high latitudes (Fig. 3f). This indicates a positive SW water vapor feedback due 357 to a positive correlation between temperature and atmospheric water vapor, which 358 leads to larger water vapor absorption of SW radiation in months with positive 359 temperature anomalies. However, since $\operatorname{SD}\left(S W_{C L E A R-A T M}\right)$ is relatively small, this 360 term makes a fairly modest contribution to interannual temperature variability 361 (Figs. 3e,g).

363 Where $\operatorname{SD}\left(S W_{A L B E D O}\right)$ is substantial, this term is positively correlated with $\Delta T$, 364 because warm anomalies typically coincide with negative anomalies in snow and 365 ice cover (Figs. 3h,i). However, there are also areas where this correlation is 366 negative. In particular, the negative correlation over Antarctica reflects a positive 367 correlation between temperature and snowfall: higher snowfall during anomalously

368 warm summer months counteracts the ageing of snow, thereby slightly increasing 369 the surface albedo (Picard et al. 2012). This feature is more pronounced in ERA370 Interim than in MERRA2 (Figs. S3-S4).

$372 C L O U D$ is also positively correlated with $\triangle T$ in most areas, and therefore generally 373 acts to amplify temperature variability (Figs. 31,m). Exceptions with a slightly 374 negative correlation include, among others, eastern tropical Pacific and parts of the

375 Southern Ocean. The physical interpretation of CLOUD is discussed in some more 376 detail in Section 4.3.

378 SURF and CONV strongly oppose each other over the oceans. In the tropics, 379 particularly over the equatorial East Pacific, SURF is large in magnitude and 380 positively correlated with $\Delta T$, and is thus strongly driving anomalies in surface air 
381 temperature (Figs. 3o,p). However, in the same areas, CONV strongly damps the

382 temperature variability, effectively diffusing out the impact of the local surface heat

383 flux anomalies (Figs. 3r,s). Over most of the mid-to-high-latitude oceans, the roles

384 of SURF and CONV are reversed, with the atmospheric heat convergence strongly

385 driving but the net surface heat flux strongly attenuating the temperature variability.

386 This picture of mainly ocean-driven temperature variability over the tropical and

387 atmosphere-driven variability over the extratropical oceans is consistent with a

388 large number of earlier studies (e.g., Bjerknes 1964, Deser and Blackmon 1993, Wu

389 and Kirtman 2007).

391 Over nearly all land areas, the variation in the net surface heat flux acts to reduce 392 the interannual temperature variability (Figs. 3o,p). This effect is modest but not 393 negligible: as averaged over the 12 months and all land, $\operatorname{SDC}(S U R F)=-0.44 \mathrm{~K}$, or $39430 \%$ of the corresponding mean of $\mathrm{SD}(\triangle T)=1.47 \mathrm{~K}$. Conversely, $\mathrm{SDC}(C O N V)$ is 395 positive over most land areas (Fig. 3s). The correlation between $C O N V$ and $\triangle T$ is 396 mostly not very strong (Fig. 3r), but exceeds 0.7 over large parts of the Greenland 397 and Antarctic ice sheets and 0.9 over East Antarctica. The high correlations in 398 Greenland and Antarctica seem to be linked to the relatively modest interannual 399 variability in the other energy balance terms over these ice sheets (left column of 400 Fig. 3). On the other hand, $C O N V$ attenuates interannual temperature variability in 401 northern South America and some other low-to-midlatitude land areas. The physical 402 interpretation of $C O N V$ is explored in more depth in Section 4.5.

\subsection{Seasonality}

We next discuss the seasonality of the six main energy terms included in Fig. 3, 407 focussing on their SDCs. Comparison between extended Northern Hemisphere 408 winter (November-to-March, NDJFM) and summer (May-to-September, MJJAS) 409 seasons reveals several differences (Fig. 4).

1. Temperature variability in extratropical latitudes is larger in the local winter than the summer season (Figs. 4a,b). The same applies to $\operatorname{SDC}\left(L W_{C L E A R}\right)$ (Figs. 4c,d). 
2. $\operatorname{SDC}\left(S W_{C L E A R-A T M}\right)$ is largest over the summer hemisphere ice sheets, in Greenland in NDJFM and in Antarctica in MJJAS (Figs. 4e,f).

3. The seasonality of $S W_{A L B E D O}$ reflects the seasonalities of snow and ice cover and incoming solar radiation. Accordingly, in the Northern Hemisphere

445 As an example that illustrates the seasonal variation in more detail, the monthly 446 contributions of the main energy balance terms to temperature variability in central

447 Finland (cf. Fig. 1) are shown in Fig. 5. At this location, there is a gradual shift from 
448 large $C O N V$ - and $L W_{C L E A R}$-dominated variability in October-March to smaller

$449 C L O U D$-dominated and $C O N V$-suppressed variability in May-August. $S W_{A L B E D O}$

450 only plays a significant role during the snowmelt season in March-April.

452 To explore the seasonal variation in another way, Fig. 6 identifies for every grid

453 box and every second month of the year the term that provides the largest positive

454 contribution to the standard deviation of temperature in this month. The broad

455 picture over the oceans is seasonally uniform to the extent that $S U R F$ tends to make

456 the largest contribution to interannual variability in the tropics and $C O N V$ at higher

457 latitudes. However, the border between the $C O N V$ - and $S U R F$-dominated zones is

458 further poleward in summer than in winter, particularly in the Northern

459 Hemisphere. $L W_{C L E A R}$ and CLOUD are also important, overriding all the other terms

460 in some months in some ocean regions. CLOUD is more frequently the foremost

461 term in summer than in winter; in particular it dominates the variability over large

462 parts of the extratropical North Pacific and North Atlantic in summer. In addition

463 to the larger insolation, this reflects the weaker midlatitude baroclinicity in summer,

464 which reduces the importance of $C O N V$ relative to the winter season. To provide

465 some more detail, diagrams similar to Fig. 5 are shown for six ocean grid boxes (in

466 the Arctic Ocean, extratropical North Atlantic and North Pacific, eastern and

467 western tropical Pacific, and high-latitude Southern Ocean) in Fig. S10.

469 Over most of the winter hemisphere continents, either CONV or $L W_{C L E A R}$ is the 470 largest contributor to temperature variability. In summer, however, CLOUD is 471 widely dominant in the extratropical continents. CLOUD is also commonly the 472 largest term in tropical land areas, although this varies with month and region.

473 Seasonal cycles of the individual energy terms in six land grid boxes (in Greenland,

474 Siberia, Central Europe, the Tibetan Plateau, Amazonia and East Antarctica) are 475 shown in Fig. S11.

477 The variations of snow and sea ice conditions make either $S W_{A L B E D O}$ or SURF the 478 largest contributor to temperature variability in some months and locations. $479 S W_{A L B E D O}$ has this position in midwinter in parts of the United States and south480 central Asia. During the spring, such areas shift northward. In May, in particular, $481 S W_{A L B E D O}$ is the largest term over much of northern Siberia and northernmost North 
482 America, as well as the Tibetan Plateau (see also Figs. S11b,d). Due to variations

483 in the ice edge position, $S W_{A L B E D O}$ is also locally dominant over the Arctic and

484 Antarctic Oceans in the local spring and summer (see also Figs. S10a,f). Variations

485 in ice conditions also dramatically affect the atmosphere-ocean heat exchange

486 during the cold season (Deser et al. 2010, Petrie et al. 2015). This locally makes

487 SURF the largest contributor to temperature variability near the sea ice edge in late

488 fall and winter, both over the Arctic Ocean and the high-latitude Southern Ocean

489 (see also Figs. S10a,f).

491 Averaging over all 12 months and the global area, $C O N V$ is the largest contributor 492 to variability in $47 \%$ of cases, followed by CLOUD (21\%), $L W_{C L E A R}(16 \%), S U R F$ 493 (14\%), and $S W_{A L B E D O}(2 \%)$. $S W_{C L E A R-A T M}$ only has this position in limited parts of 494 the Antarctic continent in the local summer (0.1\%).

496 To complement the overview provided this far, we next focus on the physical 497 interpretation of two of the major energy terms: $L W_{C L E A R}$ (Section 4.4) and CONV 498 (Section 4.5). In both cases, there are several factors involved and a more detailed 499 analysis is therefore useful.

\subsection{Factors affecting $L W_{C L E A R}$}

Using the method detailed in Appendix $\mathrm{C}$, the term $L W_{C L E A R}$ was further 504 decomposed as

$$
L W_{C L E A R}=L W_{C L E A R-S}+L W_{C L E A R-W W}+L W_{C L E A R-L R}+\varepsilon
$$

506 Here $L W_{C L E A R-S}$ represents variations in an effective surface emissivity calculated 507 from the monthly means of surface air temperature and surface upward LW 508 radiation (Eq. (C2)). In practice, this term mainly reflects variations in the surface 509 minus surface air temperature difference. The next two terms represent the main 510 factors expected to affect the atmospheric clear-sky greenhouse effect (Webb et al. 511 1993), i.e. the atmospheric water vapor content (WW) and the lapse rate between 512 the surface and the midtroposphere (LR). These terms were estimated using linear 513 regression. $\varepsilon$ is the residual from this regression. 
515 The factors that contribute to $\operatorname{SDC}\left(L W_{C L E A R}\right)$ based on (11) are analysed in Fig. 7.

516 Variations in the effective surface emissivity (term $L W_{C L E A R-S}$ ) are unimportant

517 over most land areas (Fig. 7a). However, they are more important over the mid-to-

518 high latitude oceans, particularly the northern North Atlantic, where relatively large

519 differences between the surface and surface air temperatures occur. Elsewhere,

$520 \operatorname{SDC}\left(L W_{C L E A R}\right)$ is dominated by variations in the atmospheric clear-sky greenhouse 521 effect.

523 Both the water vapour and the lapse rate variations are found to amplify temperature 524 variability in most areas (Figs. 7b,c). The lapse rate contribution (Fig. 7c) is largest 525 in areas where temperature anomalies typically have a bottom-heavy structure, so 526 that anomalies of surface temperature are not accompanied by equally large 527 anomalies aloft. This is generally the case in high latitudes (especially in winter, 528 Figs. S16-S17), but also over dry land areas such as Australia. The lapse rate 529 contribution is also substantial in the easternmost tropical Pacific, where local SST 530 variations mainly affect air temperature in the boundary layer below a 531 climatological subsidence inversion (Andrews and Webb 2018). The water vapour 532 contribution is widely dominant at lower latitudes, being particularly large over the 533 central and eastern Pacific Ocean (Fig. 7b), but is still not positive everywhere. One 534 of the exceptions is the western tropical Pacific, where the highest surface air 535 temperatures coincide with remotely forced anomalous subsidence that warms the 536 surface by reducing cloud cover but also simultaneously reduces the atmospheric water vapour (Trenberth and Shea 2005).

\subsection{Interpretation of CONV}

541 For the maps and diagrams shown this far, $C O N V$ was calculated as a residual. Here

542 we report the results obtained from the direct calculation of the term using ERA543 Interim data (Section 3.2 and Appendix A).

545 It is first necessary to note that $C_{O N V_{D I R}}(8)$ and the residual $C O N V$ are far from 546 identical. $C O N V_{D I R}$ exhibits larger interannual variability than CONV (Figs. 547 S18a,d), and the interannual standard deviation of their mutual difference exceeds $5484 \mathrm{~K}$ in many parts of the world (Fig. S18g). Given the earlier experience of 
549 numerical difficulties in the calculation of atmospheric energy flux convergence

550 (e.g., Chiodo and Haimberger 2010; Mayer and Haimberger 2012; Liu et al. 2017),

551 these differences are not unexpected. Nevertheless, the time series of $C O N V_{D I R}$ and

$552 C O N V$ are positively correlated nearly everywhere, and over most of the oceans the 553 correlation exceeds 0.7 (Figure S19). $C O N V_{D I R}$ and $C O N V$ also share broadly the 554 same statistical relationship with temperature anomalies, particularly over the 555 oceans (Figs. S18b,c,e,f). Still, the SDC of the residual estimate tends to be 556 somewhat more positive than that of the direct estimate over the midlatitude 557 continents, and less positive over the midlatitude oceans (Fig. S18i). This 558 systematic feature might reflect a mismatch between the interannual variations of 559 the atmospheric energy flux convergence and the TOA and surface energy fluxes 560 in ERA-Interim, rather than just numerical errors in $C O N V_{D I R}$.

562 Following (8), $C O N V_{D I R}$ was divided into three terms that represent the energy flux 563 convergence by the monthly mean atmospheric flow and sub-monthly variations in 564 the flow, and changes in the atmospheric energy content during a month ("storage") 565 (Fig. 8). This division reveals a strong tendency of cancellation between the 566 monthly mean and sub-monthly energy flux convergence components at 567 extratropical latitudes (Figs. 8d-i). In midlatitudes, the monthly mean energy flux 568 convergence component amplifies temperature variability (Figs. 8e-f), whereas the 569 sub-monthly component acts to reduce the variability (Figs. 8h-i) but is typically 570 slightly smaller in magnitude. Outside of midlatitudes, the situation is less clear571 cut. For example, over parts of Antarctica, sub-monthly energy flux convegence 572 appears to amplify, but monthly mean convegence to attenuate temperature 573 anomalies. In the tropics, the monthly mean component generally dominates over 574 the sub-monthly component. Finally, Fig. 8j shows that within-month changes in 575 atmospheric energy storage are a non-negligible part of CONV in individual 576 months. However, these changes neither systematically amplify nor reduce the 577 temperature variability (Fig. 81). The atmospheric energy content tends to be 578 broadly in phase with surface air temperature, and hence its change from the 579 beginning to the end of the month is nearly uncorrelated with the monthly mean 580 temperature anomaly (Fig. 8k). 
582 The tendency of sub-monthly energy flux convergence to reduce interannual

583 temperature variability in midlatitudes is consistent with earlier research. In 584 particular, Lau and Nath (1991) found a negative correlation between anomalies of 585 monthly mean temperature at the $850 \mathrm{hPa}$ level and the temperature tendencies 586 induced by synoptic-scale eddy heat fluxes (their Fig. 13). This diffusion-like 587 behavior of eddies also applies to the time mean flow, with the eddy heat fluxes 588 acting to reduce both the meridional and zonal gradients of temperature (Lau and 589 Holopainen 1984). One may therefore assume that, at least in the midlatitudes, the 590 anomalies in the sub-monthly energy flux convergence are more a consequence 591 than a cause of the monthly mean energy content (or temperature) anomalies.

593 Monthly mean energy flux convergence tends to amplify and its sub-monthly 594 counterpart to attenuate the midlatitude temperature variability in both the NDJFM 595 and MJJAS seasons (Fig. S20). Interestingly, however, the sub-monthly energy flux 596 convergence makes a more negative SDC contribution in the northern parts of 597 Eurasia and North America in summer than in winter. The tendency of CONV to 598 amplify temperature variability in winter but to rather reduce it in summer in these 599 areas (Figs. 4m,n) thus reflects a delicate balance between the contributions of the 600 monthly mean and sub-monthly energy flux convergence.

\section{Discussion}

602

603 The results of diagnostic techniques tend to become more difficult to interpret when 604 the quantity of interest (here the temperature anomaly) is a small residual of large 605 but compensating right-hand-side terms. The tendency of compensation between 606 the monthly mean and sub-monthly energy flux convergences was already 607 discussed in Section 4.5. Another equally important case is the compensation 608 between $C O N V$ and SURF over the ice-free oceans.

610 As shown in R17,

$$
\Delta(S-L)=\Delta G-\Delta\left(C-\frac{\partial E}{\partial t}\right)=-D(S U R F+C O N V)
$$

612 The compensation between $S U R F$ and CONV therefore indicates that, over the ice-

613 free oceans, the anomalies in the net TOA radiation flux $S-L$ are smaller than those

614 in the net surface energy flux $G$. In fact, the average interannual standard deviation 
615 of $G$ as calculated over the 12 months and all ocean grid boxes exceeds the standard

616 deviation of $S-L$ by more than a factor of three (not shown). This difference is

617 qualitatively explicable by the fact that the TOA radiation balance is much less

618 sensitive to variations in air temperature than the net surface energy flux is to the

619 air-sea temperature difference. Everything else being the same, a $1 \mathrm{~K}$ anomaly in $T$

620 only increases $L$, and hence reduces $S-L$, by $D \Delta T \approx 3.3 \mathrm{Wm}^{-2} \mathrm{~K}^{-1}$ (Eqs. (1) and (4)).

621 On the other hand, bulk parameterizations of turbulent energy fluxes (e.g., Kara et

622 al. 2000) indicate a change of up to several tens of $\mathrm{Wm}^{-2}$ in the net surface energy

623 flux per each $1 \mathrm{~K}$ change in the air-sea temperature difference. Over the ice-free

624 oceans, where a substantial net surface flux can be sustained by the heat capacity

625 of the ocean mixed layer, $\Delta G$ can thus easily exceed $\Delta(S-L)$ even when the anomaly

626 in the air-sea temperature difference is relatively small.

628 One may argue that the multiplicator $D^{-1} \approx 0.3 \mathrm{~K} \mathrm{~W}^{-1} \mathrm{~m}^{2}$ used in (5) exaggerates the 629 actual sensitivity of surface air temperature to variations in local energy input. This 630 is particularly the case over the ice-free ocean, due to the ability of the net surface 631 flux to consume a large fraction of any anomalous energy input into the air column.

632 However, the diffusive behavior of the sub-monthly atmospheric energy flux 633 convergence (Section 4.5) implies that the same also applies in other areas.

634 Anomalies in the energy input into an air column, regardless of whether they 635 originate from the net surface energy flux, cloudiness or, for example, surface 636 albedo, are only partly balanced by local temperature-mediated changes in the TOA 637 radiation balance. A large fraction of the energy input anomaly rather tends to be 638 exported away by the atmospheric circulation.

640 To alleviate the systematic compensations, an energy budget framework should 641 ideally take into account the effects of surface air temperature anomalies on SURF 642 and $C O N V$, rather than treating all of $S U R F$ and $C O N V$ as independent right-hand643 side terms. However, this would require a substantial extension of the method. First, 644 the energy budgets of the upper ocean and ground should be explicitly included, in 645 addition to that of the atmosphere (Hedemann et al. 2017; Liu et al. 2017). Second, 646 the effect of temperature anomalies on atmospheric horizontal energy flux 647 convegence should be parameterized as a diffusion process. The second 648 requirement is particularly difficult to achieve in a single-column framework, 
649 because the energy flux convergence is regulated by the gradients rather than the

650 absolute local values of temperature and atmospheric energy content.

652 A local and instantaneous energy budget framework cannot identify processes that 653 are non-local in space or time. For example, during an El Niño, atmospheric energy

654 flux divergence over central and eastern tropical Pacific acts to cool the air locally, 655 thereby balancing a large fraction of the anomalous net surface energy flux. 656 However, energy flux divergence in one area requires convergence elsewhere. Due 657 to the stationary Rossby waves excited by diabatic heating anomalies (Simmons 658 1982, Ji et al. 2016), this energy redistribution process is more complicated than 659 just horizontal diffusion. As another example, an anomaly in atmospheric 660 circulation in the preceding months might help to build a warm or cold anomaly in 661 the upper ocean temperature in some area, which would then feed back to the 662 atmosphere by inducing an anomalous net surface energy flux. Thus, although 663 energy budget analysis is useful for diagnosing the origin of temperature anomalies, 664 it alone will not reveal the full cause-effect chain of events.

\section{Conclusions}

668 This study has investigated the energetics of interannual temperature variability in 669 the ERA-Interim and MERRA2 reanalyses. Using the method introduced in R17, 670 the anomalies in monthly mean surface air temperature were decomposed to six 671 main components, representing the variations in (i) the atmospheric clear-sky 672 greenhouse effect, (ii) clear-sky SW radiative properties of the atmosphere, (iii)

673 surface albedo, (iv) clouds, (v) the net surface energy flux, and (vi) atmospheric 674 energy flux convergence minus storage. Based on their covariation with the actual 675 temperature anomalies, the effects of these indivual components on temperature 676 variability were then statistically diagnosed. A rich variety in the energetics of 677 temperature variability in different areas and times of the year was found, 678 depending on the surface conditions, availability of solar radiation and the local 679 meteorological characteristics. Nevertheless, the main findings are the following: a small residual of opposite contributions from the net surface heat flux and 
atmospheric energy flux convergence. In the tropics, particularly in the eastern Pacific, the net ocean-to-atmosphere heat flux provides the main energy source for temperature variability, but most of this energy input is transported away by the atmospheric circulation. This pattern is reversed at higher latitudes, where variations in atmospheric energy flux convergence are large but are mainly consumed by heating or cooling the water mass, rather than changing the surface air temperature.

2. The net surface heat flux also tends to attenuate temperature variability on land but is mostly a secondary term in the energy budget. Major energetic drivers of temperature variability over land include, depending on season and location, variations in the atmospheric energy flux convergence, clouds, the clear-sky greenhouse effect, and surface albedo. Nonetheless, atmospheric energy flux convergence reduces rather than amplifies temperature variability over large parts of Eurasia and North America in summer, partly compensating a strongly positive cloud contribution to temperature variability. The same happens in some tropical land areas, especially northern South America.

3. Care is needed in the interpretation of atmospheric energy flux convergence, which is affected by variations in both the atmospheric circulation and the atmospheric energy content and hence temperature. Thinking of anomalies of energy flux convergence simply as a cause of temperature anomalies is therefore not justified. In midlatitudes, in particular, our results reveal a duality between time scales, with anomalies in the monthly mean flow amplifying, but the sub-monthly variations attenuating temperature variability via their effect on the energy flux convergence. The net of these two very large components leaves a much smaller residual, particularly over land. The counter-intuitive situation in which the net effect of the energy flux convergence is to reduce temperature variability may arise when other components in the energy balance strongly act to amplify the variability. This is the case, for example, with cloud anomalies in much of Eurasia and 
717 The two reanalyses agree well on these general features, but some quantitative 718 differences are evident. The ERA-Interim minus MERRA2 differences in the

719 individual terms typically range from about $25 \%$ to $100 \%$ of the two-reanalysis

720 mean on the grid box scale. Perhaps unsurprisingly, the effect of clouds is one of

721 the most uncertain terms in the decomposition.

723 By analyzing the energetic contributions to the standard deviation of monthly mean 724 temperature, this study has emphasized the typical energy budget features 725 associated with temperature anomalies. Nevertheless, the correlation between the 726 individual energy budget components and temperature anomalies is far from perfect 727 (middle column of Fig. 3). Thus, a similar temperature anomaly may result from 728 different combinations of energetic contributions. Examples of this variation are 729 also readily visible in the time series of Fig. 1. For instance, although the net surface 730 heat flux typically attenuates temperature variability, it amplified the cold 731 anomalies in Januarys 2003 and 2010 (Figs 2a,b). In both cases, the cold January 732 was preceded in Finland by a very cold second half of December, which served to 733 reduce the ground-to-air heat flux by cooling the ground. Apart from this case-to734 case variability, it would be worthwhile to study to which extent the relationship 735 between energetics and temperature anomalies is (or is not) nonlinear. For example, 736 do summer months with extreme warm anomalies differ from those with moderate 737 anomalies in the relative importance of the energy balance components that 738 contribute to these anomalies?

740 To give a globally consistent overview, the analysis in this paper has covered the 741 whole world. More remains to be learned from more in-depth studies of temperature 742 variability on regional scales. Moreover, keeping in mind the issues discussed in 743 the previous section, a diagnostic energy budget approach should ideally be 744 complemented by carefully designed model experiments. Such experiments could 745 help to elucidate, for example, the remote effects of SST variability on the 746 atmospheric energy transport and hence temperature.

748 Energetics of interannual temperature variability is also important in the context of 749 climate modelling. The magnitude of interannual variability differs considerably 750 between different global and regional climate models (Räisänen 2002, de Elía et al. 
751 2013). Linking this variation to its energetic contributors could potentially help the 752 improvement of climate models. The energetics point of view might also facilitate 753 a better understanding of model-simulated future changes in temperature 754 variability. Together with the evaluation of the present-day energetics of variability 755 in the models, this could help distinguishing between more and less likely 756 projections for the future. 
The total energy in a hydrostatic air column is

$$
E=\int_{0}^{p_{s}}\left(c_{p} T+L q+k\right) \frac{d p}{g}+p_{s} h_{s}
$$

where $T$ is temperature, $q$ specific humidity, $k$ kinetic energy per unit mass, $c_{p}$ specific heat of air at constant pressure, $L$ the latent heat of vaporization, $g$ the acceleration of gravity, $p_{s}$ surface pressure and $h_{s}$ the local surface height. We treat $c_{p}=1004 \mathrm{~J} \mathrm{~kg}^{-1} \mathrm{~K}^{-1}, L=2.5 \times 10^{6} \mathrm{~J} \mathrm{~kg}^{-1}$ and $g=9.81 \mathrm{~m} \mathrm{~s}^{-1}$ as constants and neglect the effects of cloud water and ice. For a more precise formulation, see Mayer et al. (2017).

Differentiating (A1) with respect to time gives

$$
\frac{\partial E}{\partial T}=\int_{0}^{p_{S}} \frac{\partial e}{\partial T} \frac{d p}{g}+\left(\frac{e\left(p_{S}\right)}{g}+h_{s}\right) \frac{\partial p_{S}}{\partial t}
$$

where $e=c_{p} T+L q+k$. The latter term represents changes in atmospheric mass rather than in the energy content of air. It can be non-zero even with no net advection or diabatic source of energy within the air column, and is therefore neglected in our analysis (cf. Liang et al. 2017). An expression for $\partial e / \partial t$ is obtained from the thermodynamic, momentum and specific humidity equations:

$$
\frac{\partial e}{\partial t}=-\vec{U} \cdot \nabla_{3}(e+\Phi)+L S_{q}+Q-d
$$

Here $\vec{U}$ is three-dimensional wind, $\nabla_{3}$ is three-dimensional gradient operator, $\Phi$ is geopotential, $S_{q}$ is net water vapour source per unit mass, $Q$ is diabatic heating and $d$ is dissipation of kinetic energy ( $d$ also contributes to $Q$ and its net effect is therefore zero). Vertical integration of (A3) gives

$$
\int_{0}^{p_{s}} \frac{\partial e}{\partial T} \frac{d p}{g}=-\int_{0}^{p_{s}} \vec{U} \cdot \nabla_{3}(e+\Phi) \frac{d p}{g}+R_{a}+H+L E
$$

where the mass-integrated water vapour source is assumed to equal the difference between surface evaporation $(E)$ and precipitation. $R_{a}$ is the atmospheric radiation balance and $H$ the sensible heat flux from the surface. Note that $R_{a}+H+L E=$ $S-L-G($ Eqs. (1)-(2)).

The first right-hand-side term in (A4) represents the atmospheric energy flux convergence $C$, written in advection form. This term is usually converted to flux convergence form using the identity $\vec{U} \cdot \nabla_{3}(e+\Phi)=\nabla_{3} \cdot(\vec{U}(e+\Phi))$, where we 
789 have used the continuity equation $\nabla_{3} \cdot \vec{U}=\nabla_{p} \cdot \vec{V}+\frac{\partial \omega}{\partial p}=0$. An advantage of this

790 is that vertical flux convergence integrates to zero if vertical velocity at the surface

791 can be neglected. Furthermore, globally averaged horizontal convergence is zero,

792 as required by energy conservation. On the other hand, the calculation of the energy

793 flux convergence is numerically delicate. The main issue are errors in mass flux

794 convergence, the effects of which can be reduced but not fully eliminated by

795 adjusting the net mass flux to the air column (e.g., Hantel and Haase 1983; Chiodo

796 and Haimberger 2010; Mayer and Haimberger 2012; Liu et al. 2017). After testing

797 both the flux convergence and the advection form, we chose the latter since this

798 yielded a better match between $C O N V$ and $C O N V_{D I R}$ in our implementation.

800 To study how atmospheric phenomena on different time scales contribute to the

801 energy flux convergence, the monthly means of the advection term in (A4) were

802 further divided to two parts by writing

$$
-\overline{\vec{U} \cdot \nabla_{3}(e+\Phi)}=-\underbrace{\overline{\vec{U}} \cdot \nabla_{3}(\bar{e}+\bar{\Phi})}_{M O N}-\underbrace{\overline{\overrightarrow{U^{\prime}} \cdot \nabla_{3}\left(e^{\prime}+\Phi^{\prime}\right)}}_{S M}
$$

804 where the overbar denotes the monthly mean and the prime a deviation from it.

805 When integrated vertically and divided by $D$, these two components give $C O N V_{M O N}$

806 and $C O N V_{S M}$ in (8). Similarly, dividing the left-hand-side term in (A4) by $D$ gives

807 STOR in (8).

808

809 The energy flux convergence and the change in atmospheric energy content were

810 evaluated using ERA-Interim data at 6-h time resolution, $0.75^{\circ}$ horizontal

811 resolution and 37 pressure levels. The results were then aggregated to the $2.5^{\circ}$ grid

812 used in the other parts of the analysis.

813

814 


\section{Appendix B: Significance testing}

816 The sign test is based on the count of positive and negative values of a variable. If

817 both signs are equiprobable and autocorrelation is neglected, there is a $95.3 \%$

818 probability that the number of positive (or negative) values in a 37 -year time series

819 is within 13-24. Therefore, in a two-sided test, the same sign is required in at least

82025 of the 37 years for statistical significance at $5 \%$ level.

821

822 When applying the sign test to SDCs, the obvious choice is to count the number of

823 years in which the temperature anomaly associated with a given energy term agrees

824 in sign with the actual temperature anomaly. However, averaging over calendar 825 months requires normalization. From (9), the mean of SDC $(i)$ over several calendar 826 months is

$$
[S D C(i)]=[r(i) S D(i)]=\left[\frac{\operatorname{cov}(\Delta T(i), \Delta T)}{S D(\Delta T)}\right]
$$

828 where [ ] denotes averaging over months and $\mathrm{SD}(\Delta T)$ and $\mathrm{SD}(i)$ are the standard 829 deviations of temperature and its $i$ :th energy balance component. Expanding the 830 definition of covariance,

$$
[S D C(i)]=\sum_{j=1}^{N}\left[\frac{\Delta T(i)_{j} \Delta T_{j}}{S D(\Delta T)}\right] \equiv \sum_{j=1}^{N} f(i)_{j}
$$

832 where $N=37$ is the number of years. Thus, in the sign test, the positive and negative 833 values of $f(i)_{j}$ are counted. 


\section{Appendix C: Decomposition of LW CLEAR}

837 The term $L W_{C L E A R}$ represents variations in the clear-sky effective planetary

838 emissivity defined as

$$
\varepsilon_{e f f-C L E A R}=\frac{L_{C L E A R}}{\sigma T^{4}}
$$

where $L_{C L E A R}$ is the monthly mean clear-sky outgoing LW radiation and $T$ is the monthly mean surface air temperature. $\varepsilon_{e f f-C L E A R}$ can be further factored as

$$
\varepsilon_{e f f-C L E A R}=\frac{L_{C L E A R}}{L_{S \uparrow}} \cdot \frac{L_{S \uparrow}}{\sigma T^{4}} \equiv \varepsilon_{A} \varepsilon_{S}
$$

843 where $L_{S \uparrow}$ is the upward LW flux at the surface. $\varepsilon_{\mathrm{A}}$ is an inverse measure of the

844 clear-sky atmospheric greenhouse effect, whereas $\varepsilon_{S}$ is an effective surface

845 emissivity, which is affected by the actual surface emissivity, differences between

846 the surface and surface air temperatures, and sub-monthly variations of

847 temperature. The corresponding temperature anomalies are

$$
L W_{C L E A R}=L W_{C L E A R-S}+L W_{C L E A R-A}
$$

849 where

$$
L W_{C L E A R-S}=-D^{-1} \Delta \varepsilon_{S}\left[\varepsilon_{A}\right] \sigma\left[T^{4}\right]
$$

851 is the contribution from variations in effective surface emissivity and

$$
L W_{C L E A R-A}=-D^{-1} \Delta \varepsilon_{A}\left[\varepsilon_{S}\right] \sigma\left[T^{4}\right]
$$

853 represents the variations in the atmospheric clear-sky greenhouse effect.

$L W_{C L E A R-A}$ Was further decomposed using the linear regression model

$$
L W_{C L E A R-A}=\underbrace{a \Delta \sqrt{W W P}}_{L W_{C L E A R-W W}}+\underbrace{b \Delta\left(T_{S}-T_{300-700}\right)}_{L W_{C L E A R-L R}}+\varepsilon
$$

where $W W P$ is the vertically integrated water vapour path, $T_{s}$ is surface temperature and $T_{300-700}$ is the mean temperature at $300-700 \mathrm{hPa}$, broadly representing the layers

859 from which most of the longwave radiation escapes to space under typical 860 atmospheric conditions. The coefficients $a$ and $b$ were estimated from 37-year time 861 series of monthly mean data for each of ERA-Interim and MERRA2, using the same 862 values of $a$ and $b$ for all 12 months to avoid overfitting. $\sqrt{W W P}$ was preferred over $863 W W P$ since it explained a larger fraction of the variance in $L W_{C L E A R-A}$ when used 864 as the only predictor. This two-predictor model explains $83 \%$ (84\%) of the globally 865 averaged variance in $L W_{C L E A R-A}$ in ERA-Interim (MERRA2), with 
$866 \sqrt{W W P}$ alone explaining 61\% (65\%); see Fig. S14 for the geographical distribution

867 of the explained variance. As expected, the coefficients $a$ and $b$ in (C6) are positive 868 virtually everywhere (Fig. S15).

869

\section{Acknowledgments}

871 The author thanks the three reviewers for their constructive comments. This work

872 was supported by the Academy of Finland Centre of Excellence in Atmospheric

873 Science - From Molecular and Biological processes to the Global Climate (project 874 307331).

875 
Allan RP, Liu C, Loeb NG, Palmer MD, Roberts M, Smith D, Vidale P-L (2014) Changes in global net radiative imbalance 1985-2012. Geophys Res Lett 41: 5588-5597

Andrews T, Webb MJ (2018) The dependence of global cloud and lapse-rate feedbacks on the spatial structure of tropical Pacific warming. J Climate 31: 641-654

Barriopedro D, Fischer EM, Luterbacher J, Trigo RM, García-Herrera R (2011) The hot summer of 2010: Redrawing the temperature record map of Europe. Science 332: 220-224

Bjerknes J (1964) Atlantic air-sea interaction. Advances in Geophysics 10: 1-82

Black E, Blackburn M, Harrison G, Hoskins B, Methven J (2004) Factors contributing to the summer 2003 European heat wave. Weather 59: 217-223

Chiodo G, Haimberger L (2010) Interannual changes in mass consistent energy budgets from ERA-Interim and satellite data. J Geophys Res 115: D02112

de Elía R, Biner S, Frigon A (2013) Interannual variability and expected regional climate change over North America. Climate Dyn 41: 1245-1267

Dee DP and Coauthors (2011) The ERA-Interim reanalysis: configuration and performance of the data assimilation system. Quart J Roy Meteorol Soc 137: 553-597

Deser C, Blackmon MC (1993) Surface Climate Variations over the North Atlantic Ocean during Winter: 1900-1989. J Climate 6: 1743-1753

Deser C, Thomas R, Alexander M, Lawrence D (2010) The seasonal atmospheric response to projected Arctic sea ice loss in the late twenty-first century. J Climate 23: 333-351

Diaz HF, Hoerling MP, Eischeid JK (2001) ENSO variability, teleconnections and climate change. Int J Climatology 21: 1845-1862

Fischer EM, Seneviratne SI, Lüthi D, Schär C (2007) Contribution of landatmosphere coupling to recent European summer heat waves. Geophys Res Lett 34: L06707

García-Herrera R, Díaz J , Trigo RM, Luterbacher J, Fischer EM (2010) A review of the European summer heat wave of 2003. Critical Reviews in Environmental Science and Technology: 40, 267-306

Gelaro R and Coauthors (2017) The Modern-Era Retrospective Analysis for Research and Applications, Version 2 (MERRA-2). J Climate 30: 5419-5454

Hantel M, Haase S (1983) Mass consistent heat budget of the zonal atmosphere. Bonner Meteorologische Abhandlungen 29: 87

Hedemann C, Mauritsen T, Jungclaus J, Marotzke J (2017) The subtle origins of surface-warming hiatuses. Nature Climate Change 7: 336-340

Holmes CR, Woolling T, Hawkins E, de Vries H (2016) Robust future changes in temperature variability under greenhouse gas forcing and the relationship with thermal advection. J Climate 29: 2221-2236

Holton JR, Hakim GJ (2012) An Introduction to Dynamic Meteorology, $5^{\text {th }}$ edition. Academic Press, $552 \mathrm{pp}$

Hu X, Yang S, Cai M (2016) Contrasting the eastern Pacific El Niño and the central Pacific El Niño: process-based feedback attribution. Climate Dyn 47: 24132424 
Ji X, Neelin JD, Mechoso CR (2016) Baroclinic-to-barotropic pathway in El Niño - Southern Oscillation teleconnections from the viewpoint of a barotropic Rossby wave source. J Atmos Sci 73: 4989-5002

Kara AB, Rochford PA, Hurlburt HE (2000) Efficient and accurate bulk parameterizations of air-sea fluxes for use in general circulation models. $\mathrm{J}$ Atmos Oceanic Technol 17: 1421-1438

Kushnir Y (1994) Interdecadal variations in North Atlantic sea surface temperature and associated atmospheric conditions. J Climate 7: 141-157

Lau N-C, Holopainen EO (1984) Transient eddy forcing of the time-mean flow as identified by geopotential tendencies. J Atmos Sci 41: 313-328

Lau N-C, Nath MJ (1991) Variability of the baroclinic and barotropic transient eddy forcing associated with monthly changes in the midlatitude storm tracks. J Atmos Sci 48: 2589-2613

Liang M, Czaja A, Graversen R, Tailleux R (2017) Poleward energy transport: is the standard definition physically relevant at all time scales? Clim Dyn, doi: 10.1007/s00382-017-3722-x

Liu C, Allan RP, Mayer M, Hyder P, Loeb NG, Roberts CD, Valdivieso M, Edwards JM, Vidale P-L (2017) Evaluation of satellite and reanalysis-based global net surface energy flux and uncertainty estimates. J Geophys Res Atmos 122: 6250-6272

Loeb NG, Doelling DR, Wang H, Su W, Nguyen C, Corbett JG, Liang L, Mitrescu C, Rose FG, Kato S (2018) Clouds and the Earth's Radiant Energy System (CERES) Energy Balanced and Filled (EBAF) Top-of-Atmosphere (TOA) Edition-4.0 data product. J Climate 31: 895-918

Lu J, Cai M (2009) A new framework for isolating individual feedback processes in coupled general circulation climate models. Part I: formulation. Clim Dyn 32: $873-885$

Mayer M, Haimberger L (2012) Poleward atmospheric energy transports and their variability as evaluated from ECMWF reanalysis data. J Climate 25: 734-752

Mayer M, Haimberger L, Edwards JM, Hyder P (2017) Toward consistent diagnostics of the coupled atmosphere and ocean energy budgets. J Climate 30: $9225-9246$

Paik S, Min S-K (2017) Climate responses to volcanic eruptions assessed from observations and CMIP5 multi-models. Clim Dyn 48: 1017-1030

Park T-W, Jeong J-H, Deng Y, Zhou R, Cai M (2015) Quantitative decomposition of radiative and non-radiative contributions to temperature anomalies related to siberian high variability. Clim Dyn 45: 1207-1217

Petrie RE, Shaffrey LC, Sutton RT (2015) Atmospheric impact of Arctic sea ice loss in a coupled ocean-atmosphere simulation. J Climate 28: 9606-9622

Picard G, Domine F, Krinner G, Arnaud L, Lefebvre E (2012) Inhibition of the positive snow-albedo feedback by precipitation in interior Antarctica. Nature Climate Change 2: 795-798

Räisänen J (2002) $\mathrm{CO}_{2}$-induced changes in interannual temperature and precipitation variability in 19 CMIP2 experiments. J Climate 15: 2395-2411

Räisänen J (2017) An energy balance perspective on regional $\mathrm{CO}_{2}$-induced temperature changes in CMIP5 models. Clim Dyn 48: 3441-3454 
969 Randles CA and Coauthors (2017) The MERRA-2 aerosol reanalysis, 1980 onward.

972 Robock A (2000) Volcanic eruptions and climate. Rev Geophys 38: 191-209

973 Simmons AJ (1982) The forcing of stationary wave motion by tropical diabatic

974 heating. Quart J R Met Soc 108: 503-534

975 Taylor KE, Crucifix M, Braconnot P, Hewitt CD, Doutriaux C, Broccoli AJ, Mitchell JFB, Webb MJ (2007) Estimating shortwave radiative forcing and response in climate models. J Climate 20: 2530-2543

Trenberth KE, Fasullo JT (2013) Regional energy and water cycles: transports from ocean to land. J Climate 26: 7837-7851

Trenberth KE, Shea DJ (2005) Relationships between precipitation and surface temperature. Geophys Res Lett 32: L14703

Webb MJ, Slingol A, Stephens GL (1993) Seasonal variations of the clear-sky greenhouse effect: the role of changes in atmospheric temperatures and humidities. Clim Dyn 9: 117-129

986 Wu R, Kirtman BP (2007) Regimes of seasonal air-sea interaction and implications for performance of forced simulations. Clim Dyn 29: 393-410

988 Yang X, DelSole T (2012) Systematic comparison of ENSO teleconnection patterns 989 between models and observations. J Climate 25: 425-446

990 Yu B, Zhang X (2015) A physical analysis of the severe 2013/2014 cold winter in $991 \quad$ North America. J Geophys Res 120: 10,149-10,165

992 Zwiers FW, Kharin VV (1998) Intercomparison of interannual variability and 993 potential predictability: an AMIP diagnostic subproject. Climate Dyn 14: 994 $517-528$

995 


\section{Tables}

997

998 Table 1. Correlation of $\Delta T$ and its main energy balance components between the ERA-

999 Interim and MERRA2 reanalyses

1000

\begin{tabular}{llll}
\hline & IAV & SD & SDC \\
$\Delta T$ & 0.92 & 0.98 & 0.98 \\
$L W_{\text {CLEAR }}$ & 0.91 & 0.90 & 0.86 \\
SW & & & \\
CLEAR-ATM & 0.24 & 0.29 & 0.43 \\
SW & & & \\
ALBEDO & 0.72 & 0.86 & 0.72 \\
SLOUD & 0.57 & 0.70 & 0.56 \\
CONV & 0.85 & 0.96 & 0.90 \\
\hline
\end{tabular}

1001 IAV $=$ spatiotemporal correlation of interannual variability $(37$ years $\times 12$ months $\times$

1002 global area); SD and SDC: the correlation of the SDs and SDCs (12 months $\times$ global area) 1003

1004 
1005 Figure captions
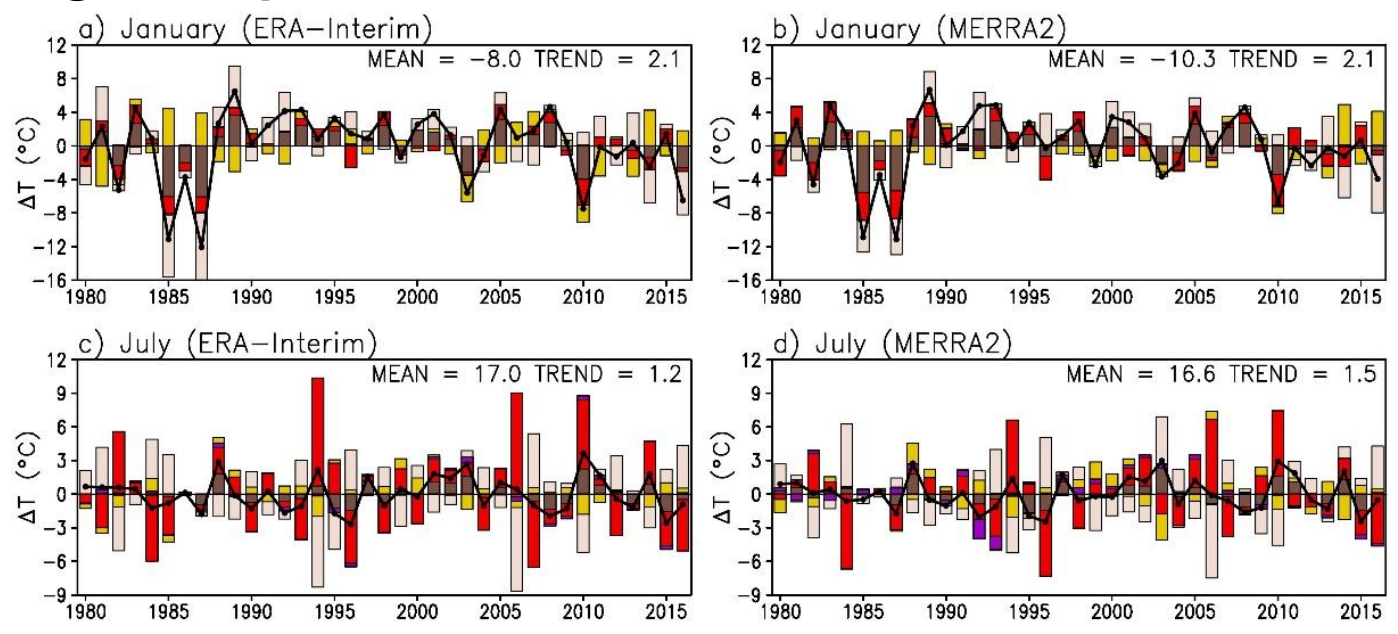

1006

$$
\begin{array}{|l}
\square \text { LWLEAR } \\
\square \text { SW } \\
\hline
\end{array}
$$

1007 Fig. 1. Linearly detrended temperature anomalies in central Finland $\left(62.5^{\circ} \mathrm{N}, 25^{\circ} \mathrm{E}\right)$ in

1008 January and July 1980-2016 (solid lines) and the contributions of individual energy

1009 balance terms to them (bars, legend at the bottom). For reference, the mean and the 36-

1010 year linear trend of temperature are given in the top-right corner of the figure panels
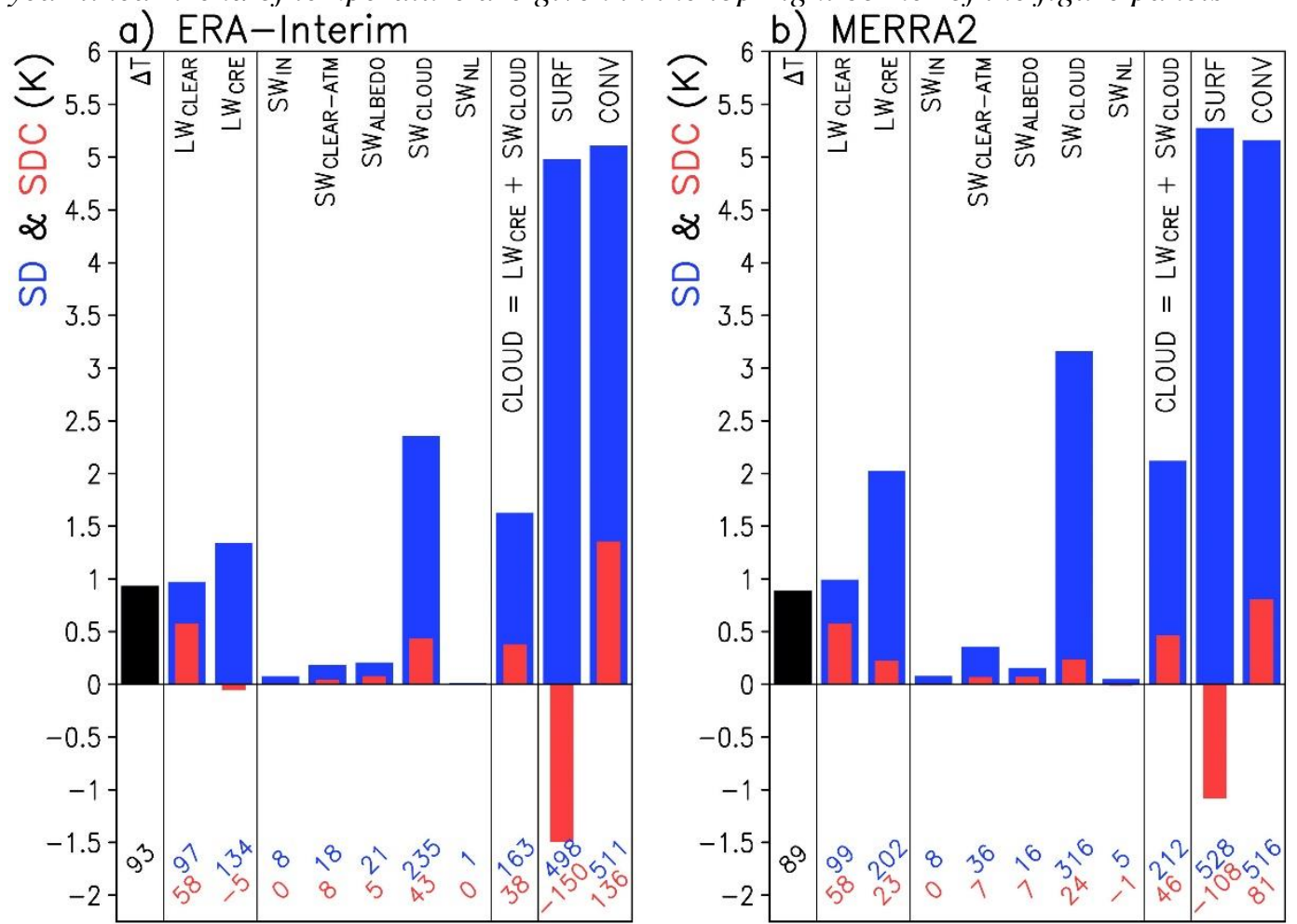

1012 Fig. 2. Typical magnitudes of the terms in Eqs. (5)-(7) in the ERA-Interim and MERRA2

1013 reanalyses. The first column shows the interannual standard deviation (SD) of monthly

1014 temperature anomalies $(\Delta T)$ averaged over the 12 months and the global area. The

1015 remaining columns show the corresponding SDs of the energy balance terms (blue) and 
1016 their contribution to the standard deviation of $\Delta T$ (SDC, red). The numeric values at the

1017 bottom give the SDs (upper) and SDCs (lower) in units of $0.01 \mathrm{~K}$ $\mathrm{SD}(\mathrm{K})$

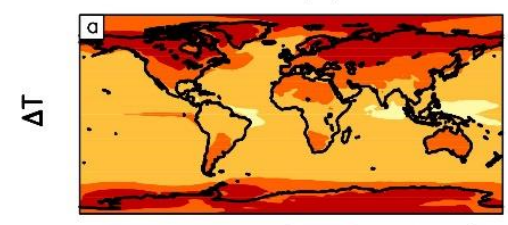

Correlation with $\Delta \mathrm{T}$
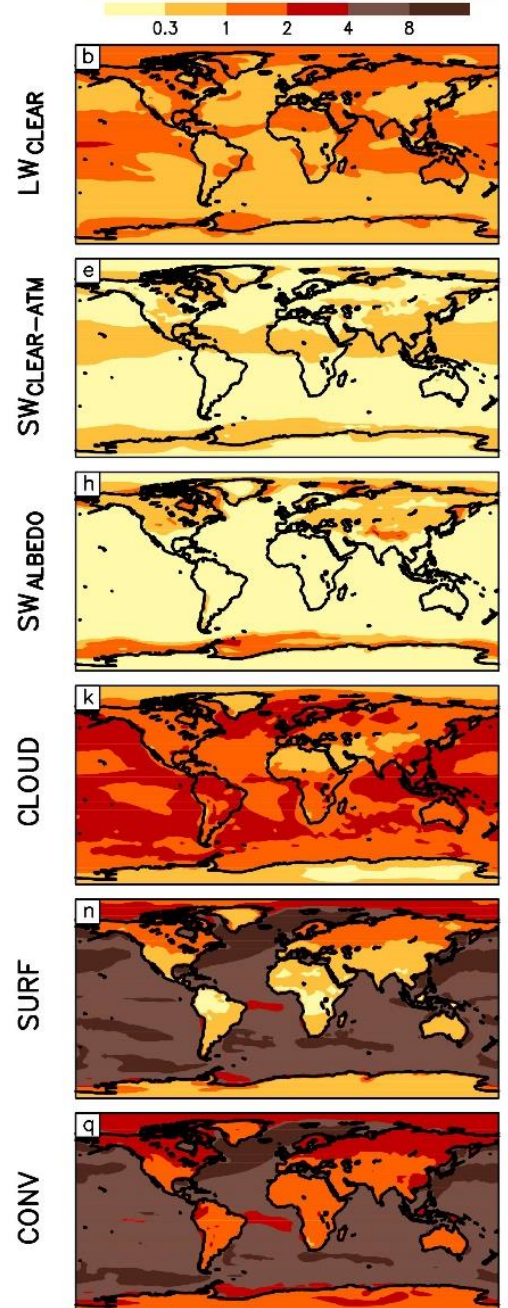
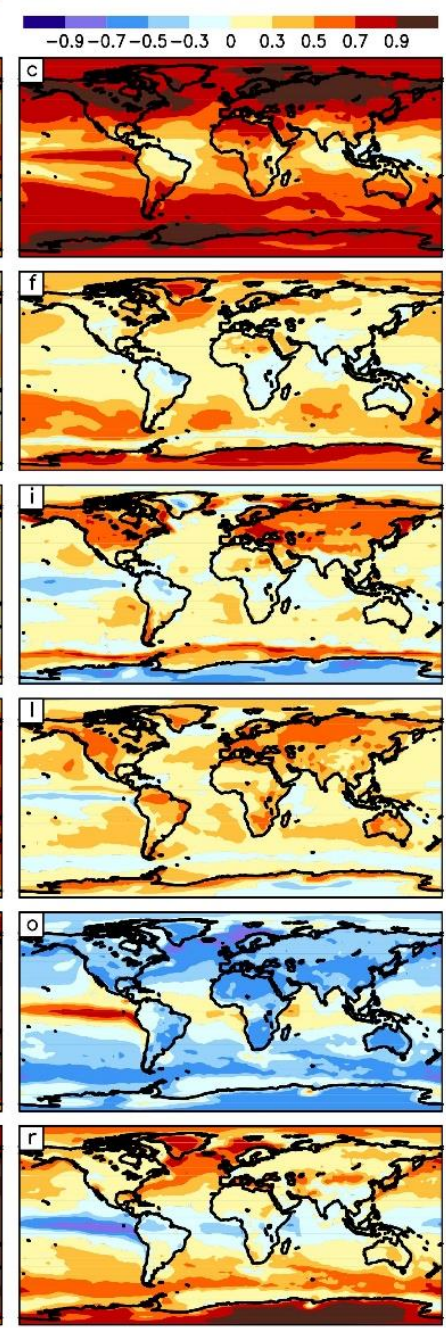

Contribution to $\mathrm{SD}(\Delta \mathrm{T})(\mathrm{K})$
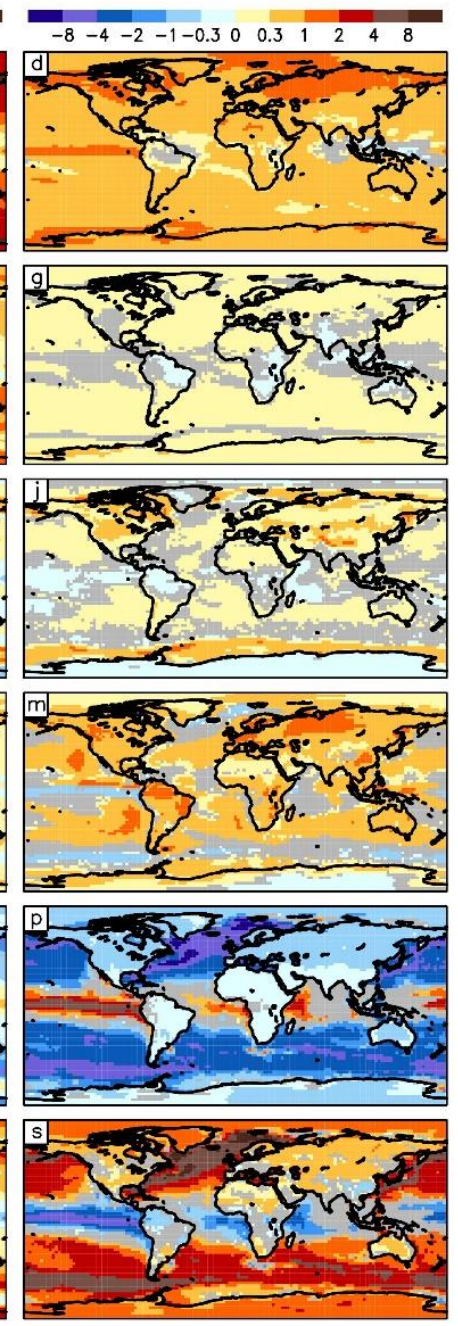

1019 Fig. 3. Left: interannual standard deviation of monthly mean temperature anomalies $(\Delta T)$

1020 and their main energy balance components. Middle: correlation between the individual

1021 energy balance components and $\Delta T$. Right: Contributions of the individidual energy

1022 balance components to the standard deviation of $\Delta T$. All statistics are averaged between

1023 ERA-Interim and MERRA2. In the third column, grey colour indicates areas where the sign

1024 of the standard deviation contribution is not robust (see Section 4.2 for definition) 

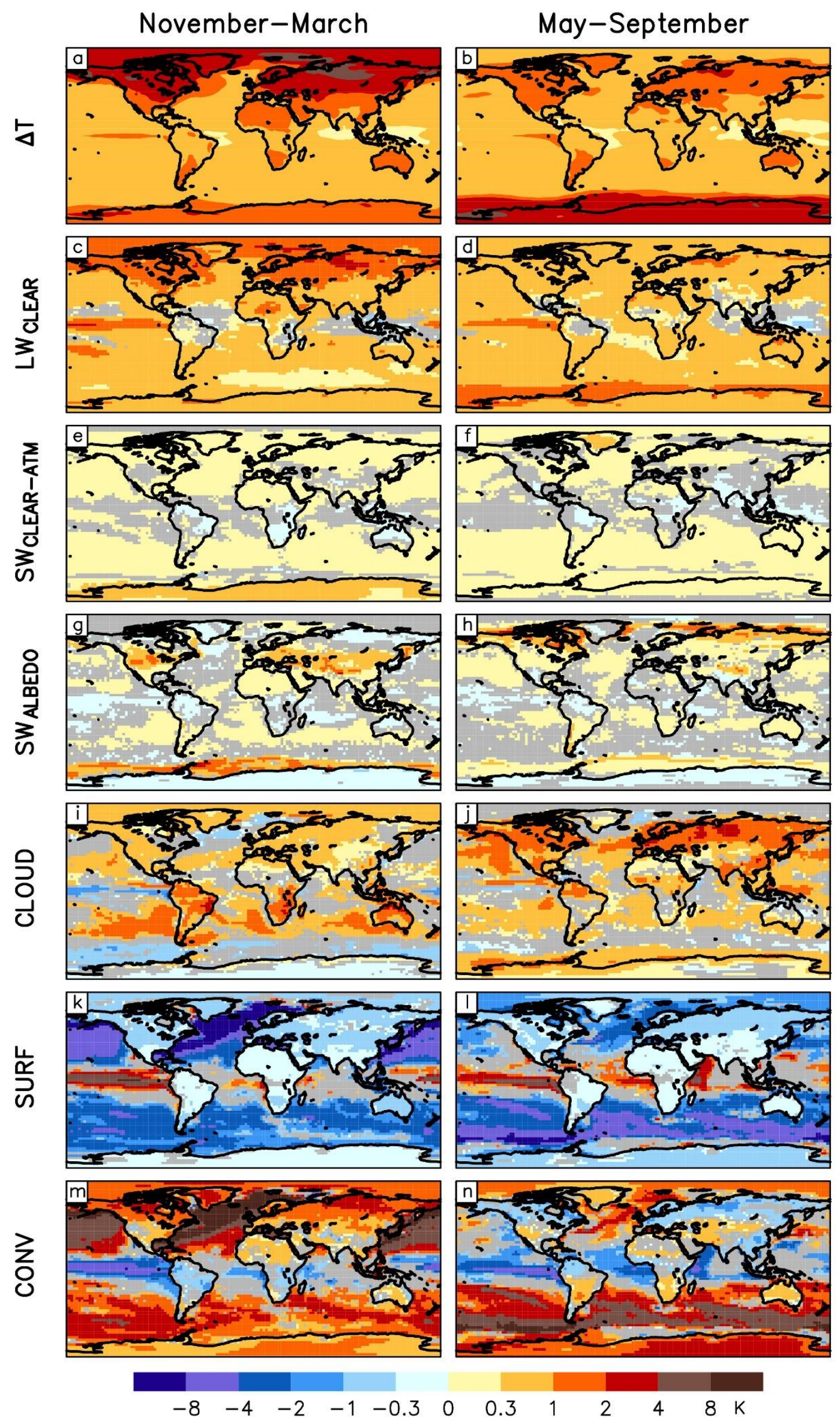
1027 Fig. 4. Interannual standard deviation of monthly mean temperature anomalies in (a) 1028 November-March and (b) May-September, and (c-n) the contributions of the main energy 1029 balance components to it. All statistics are averaged between ERA-Interim and MERRA2. 1030 Grey colour indicates areas where the sign of the standard definition contribution is not 1031 robust (see Section 4.2 for definition) 


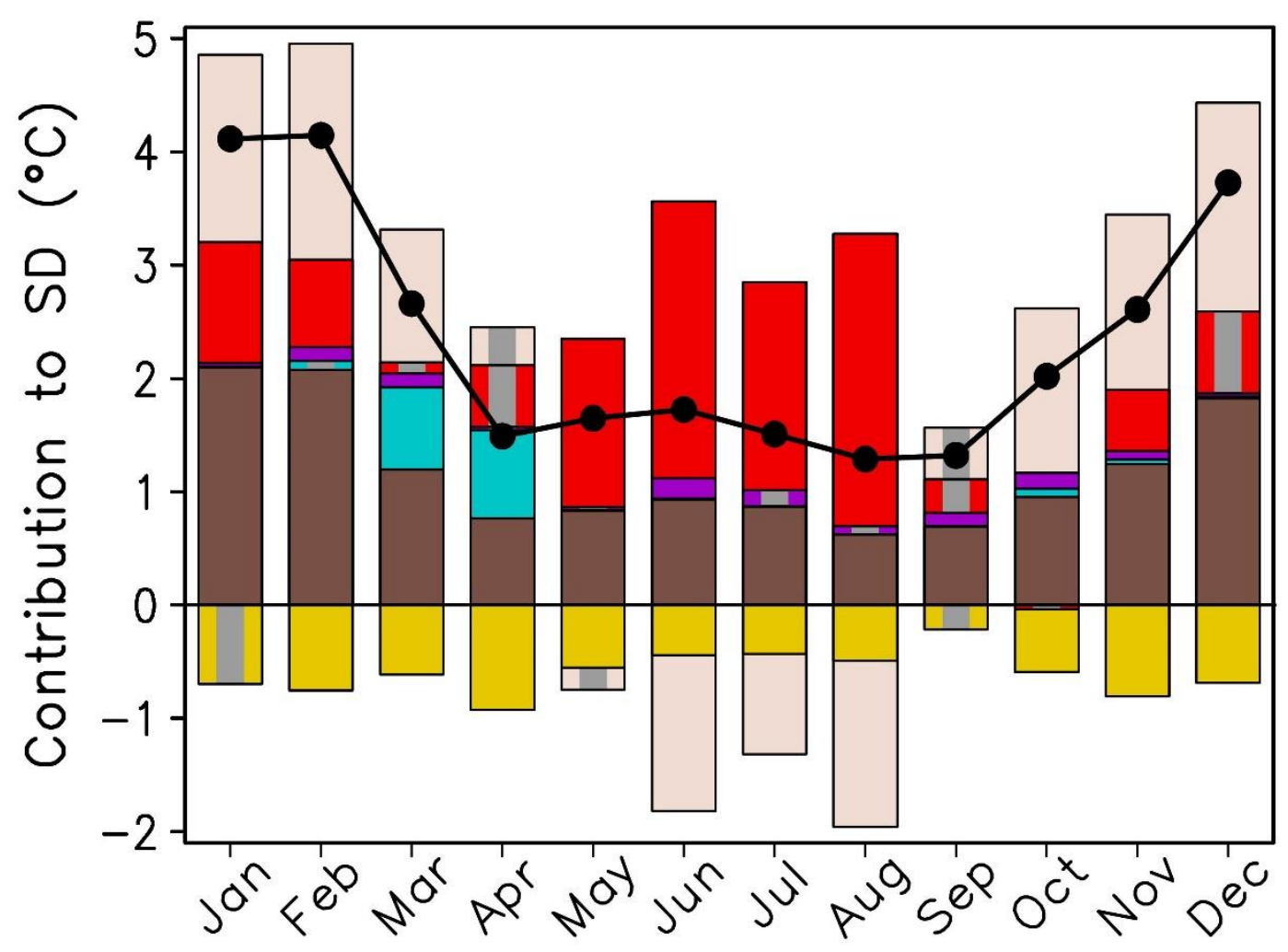

1032

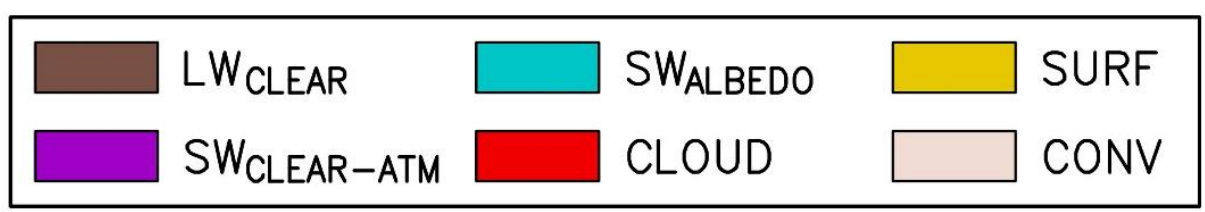

1033 Fig. 5. Interannual standard deviation of temperature in central Finland (the same grid

1034 box as in Fig. 1) (solid line) and the contributions of the six main energy balance terms to

1035 it (bars, legend at bottom; contributions that are not robust in the sense defined in Section 10364.2 are indicated with a grey core) 

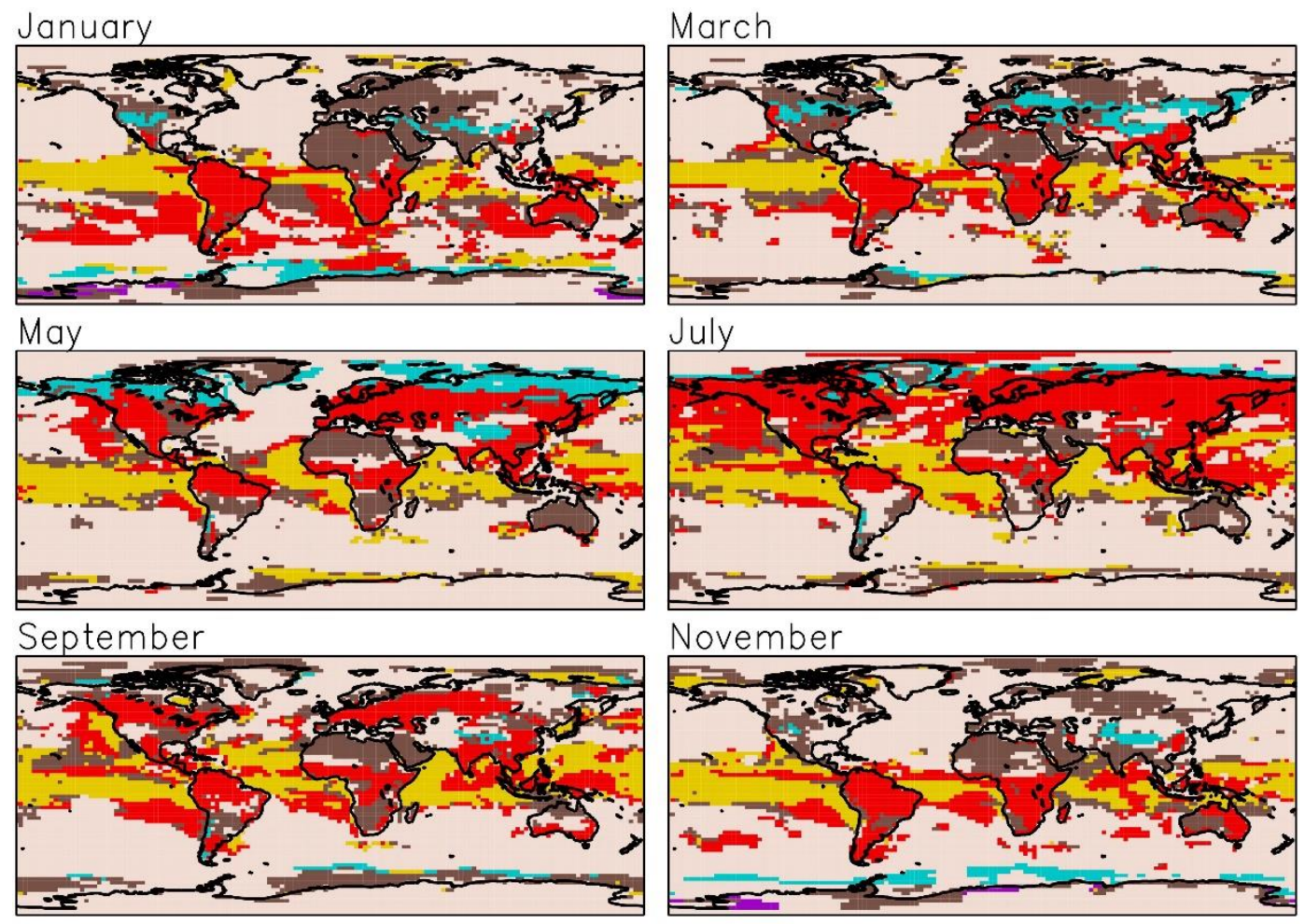

\begin{tabular}{|c|c|c|}
\hline$\square$ LW CLEAR & SW & SURF \\
\hline SW & CLOUD & CONV \\
\hline
\end{tabular}

1038 Fig. 6. Largest contributors to interannual temperature variability in 6 calendar months,

1039 based on the mean of the ERA-Interim and MERRA2 results
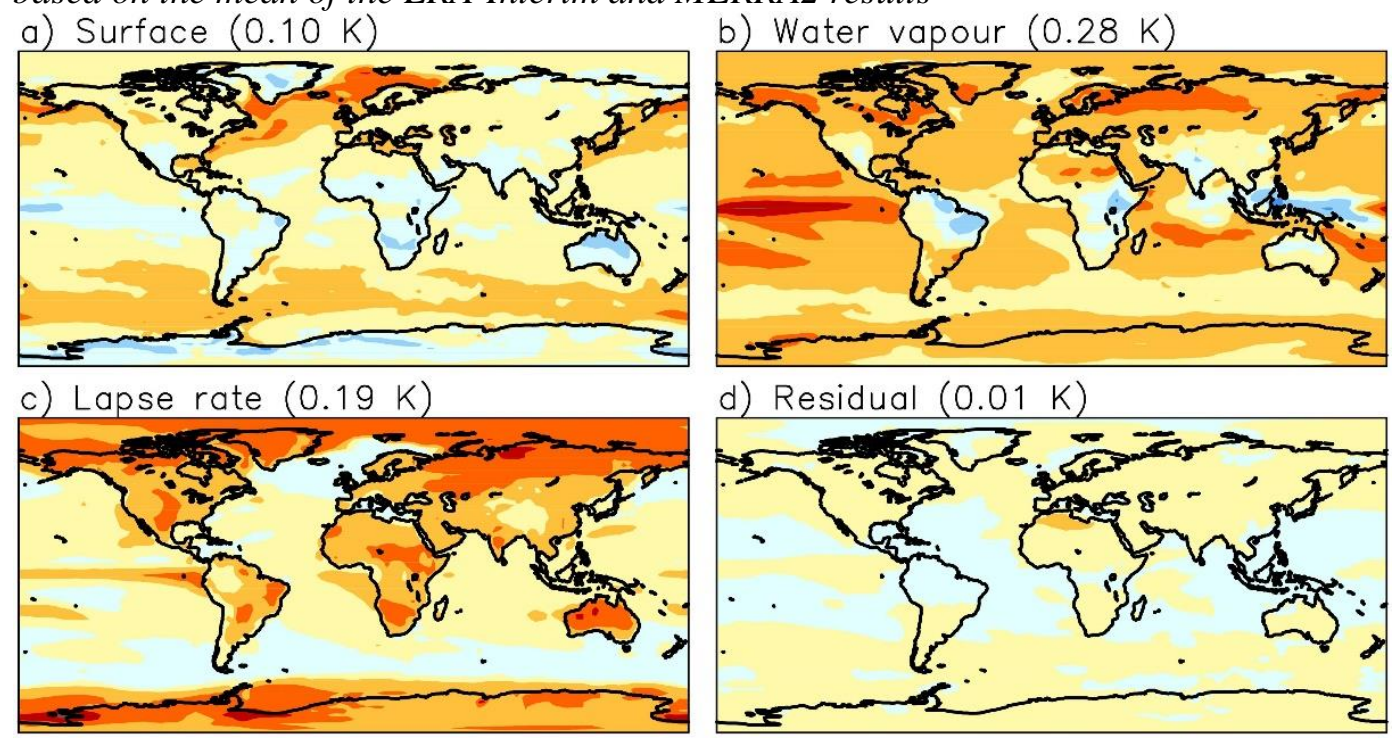

e) Total $(0.58 \mathrm{~K})$

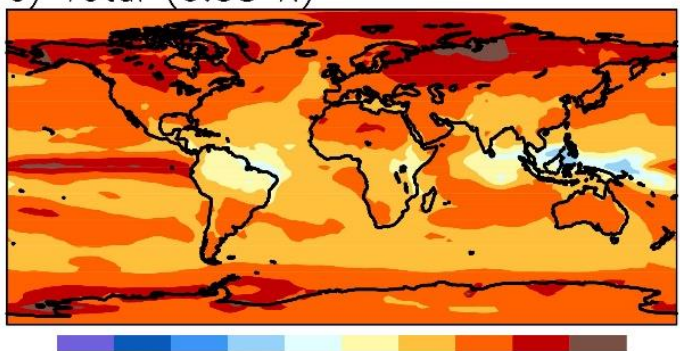

$\begin{array}{lllllll}-1.5-1 & -0.5-0.2 & 0 & 0.2 & 0.5 & 1 & 1.5 \mathrm{~K}\end{array}$ 
1041 Fig. 7. Division of $\operatorname{SDC}\left(L W_{C L E A R}\right)$ (e) to contributions from the four terms in Eq. (11) (a-

1042 d). All values are averaged over the 12 months and between ERA-Interim and MERRA2.

1043 The global area means are given in the headings. Note that the colour scale differs from

1044 Figs. 3-4

SD (K)
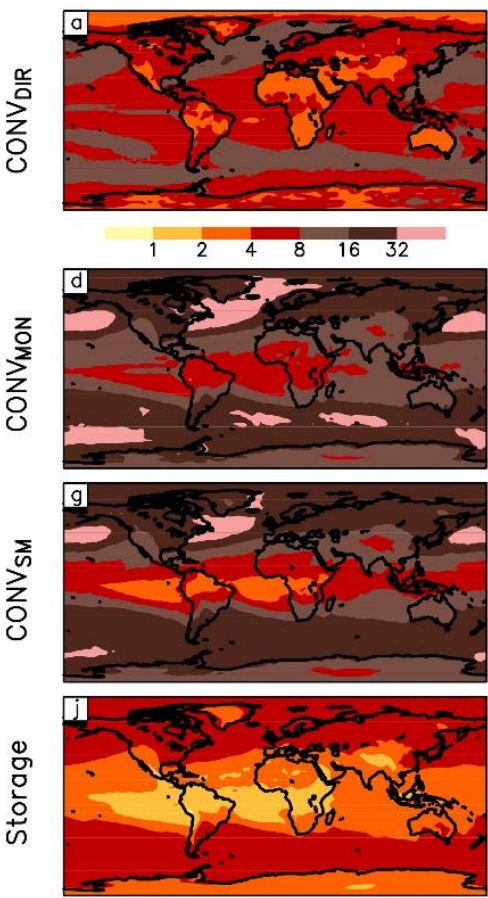

Correlation with $\Delta T$

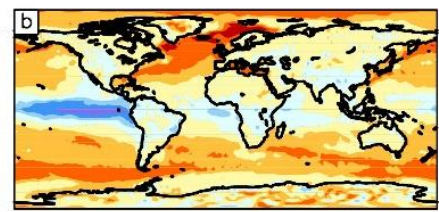

$\begin{array}{llllllll}-0.9-0.7-0.5-0.3 & 0 & 0.3 & 0.5 & 0.7 & 0.9\end{array}$
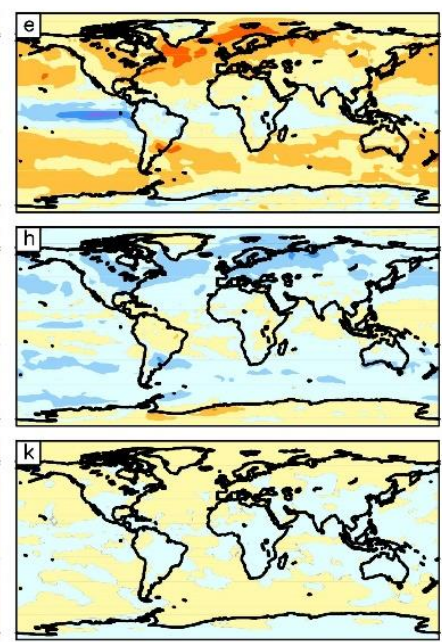

Contribution to $\mathrm{SD}(\Delta \mathrm{T})(\mathrm{K})$

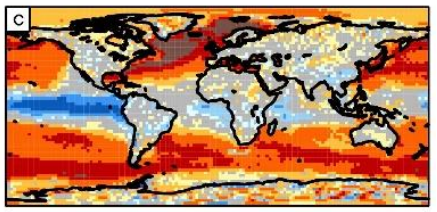

$\begin{array}{llllllll}-16-8-4-2-1 & 0 & 1 & 2 & 4 & 8 & 1632\end{array}$
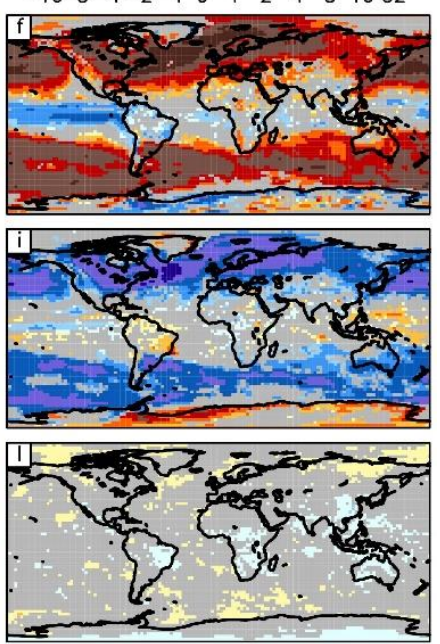

Fig. 8. Term CONV as calculated directly from energy flux converegence and storage using

1047 ERA-Interim data (a-c), and its decomposition to the contributions of (d-f) the monthly

1048 mean flow, $(g-i)$ sub-monthly flow variations and (j-l) atmospheric energy storage. The

1049 three columns are the same as in Fig. 3. Grey colour indicates areas where the sign of the

1050 standard definition contribution is not significant at 5\% level based on a sign test 